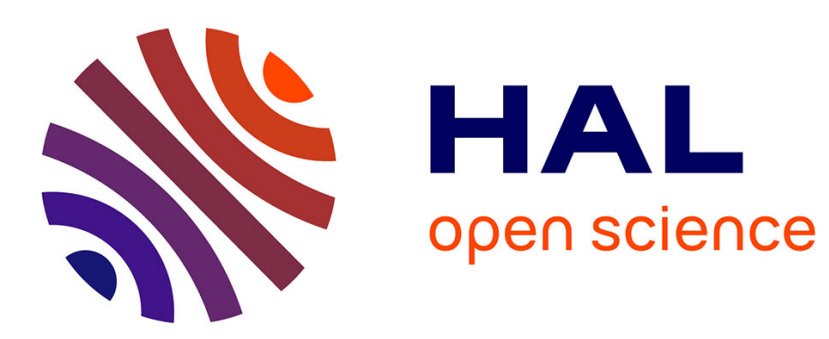

\title{
Creep of a porous rock and associated acoustic emission under different hydrous conditions \\ D. Grgic, David Amitrano
}

\section{To cite this version:}

D. Grgic, David Amitrano. Creep of a porous rock and associated acoustic emission under different hydrous conditions. Journal of Geophysical Research: Solid Earth, 2009, 114 (B10), pp.B10201. 10.1029/2006JB004881 . insu-00498751

\section{HAL Id: insu-00498751 \\ https://hal-insu.archives-ouvertes.fr/insu-00498751}

Submitted on 12 Aug 2021

HAL is a multi-disciplinary open access archive for the deposit and dissemination of scientific research documents, whether they are published or not. The documents may come from teaching and research institutions in France or abroad, or from public or private research centers.
L'archive ouverte pluridisciplinaire HAL, est destinée au dépôt et à la diffusion de documents scientifiques de niveau recherche, publiés ou non, émanant des établissements d'enseignement et de recherche français ou étrangers, des laboratoires publics ou privés.

$$
\text { Copyright }
$$




\title{
Creep of a porous rock and associated acoustic emission under different hydrous conditions
}

\author{
D. Grgic ${ }^{1}$ and D. Amitrano ${ }^{2}$ \\ Received 30 November 2006; revised 8 August 2008; accepted 24 June 2009; published 1 October 2009.
}

[1] Static fatigue of a polycrystalline porous rock (iron ore) was studied by performing multistep uniaxial creep tests under partially saturated conditions, and the impact of water saturation on creep was analyzed. Recorded strains and acoustic emissions (AE) show that water saturation induces a strong increase in AE activity and dilatant inelastic volumetric strain and a decrease in Young's modulus and in the $b$ value of the GutenbergRichter law (i.e., the relative number of large-amplitude events increases) as the rock approaches failure, indicating that microfracturing plays an important role in the creep process. Water saturation accelerates static fatigue through hydromechanical coupling and subcritical stress corrosion cracking. The chemical reactions involved in the corrosion of iron ore and leading to a decrease in its intrinsic mechanical properties are described. These reactions play a major role in the static fatigue of iron ore, which on a large scale is probably the main mechanism explaining certain collapses in underground iron mines. It is also shown that creep straining of iron ore is reversible after stress removal, indicating that it results also from a time-dependent viscoplastic mechanism (i.e., dislocation creep).

Citation: Grgic, D., and D. Amitrano (2009), Creep of a porous rock and associated acoustic emission under different hydrous conditions, J. Geophys. Res., 114, B10201, doi:10.1029/2006JB004881.

\section{Introduction}

[2] The long-term mechanical behavior of rocks is of prime importance for many geological hazards (e.g., landslides, rockfalls, and volcanoes) as well as for the stability of man-made structures (underground mines, road cuts, and open pits). In some shallow environments (e.g., natural slopes, open cut excavations), rocks exist in partially saturated conditions which can evolve with time according to variations in the relative humidity $h_{r}$ of the atmosphere. In underground mines, rocks are also partially saturated because of artificial ventilation. These variations in liquid saturation may have a large impact on mechanical behavior since they imply variations in capillary pressure and, depending on the porosity and on the shape of the porous network, variations in the effective stress.

[3] In the particular case of deep ( $\sim 200 \mathrm{~m})$ underground iron mines in Lorraine (Northeastern France), rocks are saturated (i.e., are below the water table) before mining. During mining, the water table is lowered, since mine drainage is pumped from the mine and ventilation of rooms induces drying of the rocks. At the end of mining, water is no longer pumped from the mine which can lead to mine flooding. Some mine collapses have occurred during this transient stage of flooding, often because of the failure of

\footnotetext{
${ }^{1}$ Laboratoire Environnement, Géomécanique et Ouvrages, Nancy Université, Vandoeuvre-lès-Nancy, France.

${ }^{2}$ LIRIGM, Université Joseph Fourier, Grenoble, France.

Copyright 2009 by the American Geophysical Union. 0148-0227/09/2006JB004881\$09.00
}

iron ore pillars. Therefore, knowledge of static fatigue under saturated and partially saturated conditions is important for estimating the long-term stability of such rock structures.

[4] Static fatigue of rocks has been investigated using constant stress tests [e.g., Masuda, 2001; Kranz, 1980; Kranz et al., 1982; Lajtai et al., 1987] or constant strain rate tests [e.g., Masuda et al., 1988] performed under saturated, dry (unsaturated) and ambient humidity (partially saturated) conditions. These studies have shown that timedependent weakening is much more important for a saturated rock than for a dry one, and that the time to failure may decrease by several orders of magnitude for saturated rocks compared to dry rocks. In addition, it has been shown [e.g., Lajtai et al., 1987] that the weakening effect of water is more significant in long-term experiments than in shortterm ones (for example, instantaneous loading). A physical explanation for these results may be the enhancement of subcritical crack growth by stress corrosion at crack tips which is often considered to be the main cause of timedependent brittle behavior of rocks [e.g., Atkinson, 1984].

[5] However there is a lack of studies on time-dependent behavior of rocks under partially saturated conditions in which water vapor pressure is well controlled. For iron ore, a very porous silicate rock, its short-term mechanical behavior has been characterized under saturated [Grgic et al., 2003] and partially saturated [Grgic et al., 2005] conditions, and its time-dependent deformation behavior has been studied under saturated conditions [Grgic et al., 2003]. In this paper, we focus on the time-dependent behavior of iron ore in the partially saturated domain and on the consequences of immersion in water during creep 
tests. Viscoplastic and microcracking mechanisms are considered in order to explain the time-dependent deformation of iron ore. The influence of water is analyzed by considering the hydromechanical and physicochemical (stress corrosion) effects of water. Creep tests were performed and acoustic emissions (AE) were recorded during some of the experiments. These results, and the associated experimental techniques, are transposable to other porous silicate rocks since the analyses are based on the same interactions between the porous medium and the water.

\section{Theoretical Considerations}

\subsection{Kelvin Law}

[6] Isothermal equilibrium between liquid water and its vapor in a porous medium is given by the Kelvin law:

$$
\ln \left(\frac{p_{v}}{p_{v}^{0}}\right)=\ln h_{r}=\frac{-M_{v}}{R T \rho_{l}} p_{c}
$$

where $h_{r}$ is the relative humidity, $p_{v}$ is the partial pressure of water vapor, $p_{v}^{0}$ is the vapor pressure under thermodynamic equilibrium, $p_{c}$ is the capillary pressure, $\rho_{l}$ is the density of liquid water, $R$ is the gas constant, $M_{v}$ is the molar mass of water vapor and $T$ is the absolute temperature.

[7] The partial pressure of water vapor, and therefore the capillary pressure (also called capillary suction or matrix suction), is imposed in the porous medium thanks to the saturated salt solutions method [International Organization for Standardization, 2005] used in our experiments (the partial pressure of water vapor depends on the chemical composition of the salt solution).

\subsection{Partition of Stress and Strain}

[8] Let the total strain tensor be additively decomposed (equation (2)) into the time-independent elastic component (instantaneously reversible) and the nonlinear inelastic component. Overall, in the field of rock mechanics, the latter component corresponds to an instantaneous plastic deformation and a time-dependent viscoplastic (or creep) deformation. Plasticity and viscoplasticity concepts are used in constitutive laws (thanks to mathematical tools such as the yield function, plastic or viscoplastic potential, and flow rule), provided that appropriate thermodynamic conditions (e.g., the nonnegativity of the intrinsic dissipation) are respected, in order to describe inelastic deformation, i.e., above the elastic limit. Within this constitutive modeling, the "unified approach" is based on the precept that the same mechanisms govern both plastic and viscoplastic deformation, the only difference being that the time factor is introduced in the latter. These mechanisms are displacements of crystal lattice defects and/or subcritical microcracking, the latter being assisted by stress corrosion at crack tips. In order to avoid any confusion with the terminology used in the geophysical rock deformation community, the inelastic component is decomposed into a viscoplastic component, implying time-dependent plastic deformation, and a brittle component, implying timedependent microcracking:

$$
\underline{\underline{\varepsilon}}=\underline{\underline{\varepsilon}}^{e}+\underline{\underline{\varepsilon}}^{i n} \quad \underline{\underline{\varepsilon}}=\underline{\underline{\varepsilon}}^{i p}+\underline{\underline{\varepsilon}}^{b}
$$

where superscripts " $e$," "in," " $v p$ " and " $b$ " denote, respectively, the elastic, inelastic, viscoplastic, and brittle components of the strain tensor.

[9] The two first invariants of the inelastic strain tensor, the volumetric strain $\varepsilon_{v}^{i n}$ and the distortion $\gamma^{i n}$ (i.e., the shear deformation or Von Mises equivalent deformation), are written as follows:

$$
\varepsilon_{v}^{i n}=\varepsilon_{11}^{i n}+\varepsilon_{22}^{i n}+\varepsilon_{33}^{i n} \quad \gamma^{i n}=\sqrt{\frac{2}{3} \underline{\underline{e}}^{i n}: e^{i n}} \quad \underline{\underline{e}}^{i n}=\underline{\underline{e}}^{i n}-\frac{\varepsilon_{v}^{i n}}{3} \underline{1}
$$

where $e^{i n}$ is the deviatoric strain.

[10] The corresponding invariants of the Cauchy stress tensor are $\sigma_{m}$ and $\sigma_{e q}$, the mean stress and the shear stress (or Von Mises equivalent stress), respectively:

$$
\sigma_{m}=\frac{\sigma_{11}+\sigma_{22}+\sigma_{33}}{3} \quad \sigma_{e q}=\sqrt{\frac{3}{2} \underline{\underline{S}}: \underline{\underline{S}}} \quad \underline{\underline{S}}=\underline{\underline{\sigma}}-\sigma_{m} \underline{\underline{1}}
$$

where $s$ is the deviatoric stress.

[11] Both viscoplastic and brittle processes result in creep and could be active during constant load (creep) tests and constant stress rate tests. In the ductile regime of inelastic flow, only the time-dependent plastic mechanism is active whereas both time-dependent microcracking and plastic mechanisms are active in the semibrittle regime. In naturally deformed polycrystalline rocks, solution-precipitation creep (i.e., a grain boundary dissolution-precipitation process) is also a mechanism of ductile deformation that could occur. This mechanism, which is especially rapid in rock salt even at room temperature [Ter Heege et al., 2005; Urai and Spiers, 2007], is not significant in rocks like iron ore.

[12] The nonlinear viscoplastic deformation $\varepsilon^{v p}$ during "normal" transient creep is (partially or totally) reversible if the applied stress is removed. This behavior, known as "inverse" transient creep, is related to the "reversible plasticity" of crystals [Boyko et al., 1994]. The "recoverable" time-dependent behavior is also termed anelasticity [e.g., Blum, 2001], which is linked to a relaxation phenomenon and can be modeled within viscoelasticity theory. In this paper we will not take into account these delayed elasticity effects. This reversible behavior has been observed for metallic alloys [Boyko et al., 1994; Natsik et al., 2003] and soft polycrystalline rocks like rock salt [Hunsche and Hampel, 1999] and gypsum rock [Hoxha et al., 2005]. It will be shown (section 5.1.), using strain and AE measurements, that a polycrystalline porous rock like iron ore also exhibits such behavior during creep tests, providing evidence that time-dependent inelasticity results also from a plastic mechanism (i.e., dislocation creep), even at room temperature and pressure.

\section{Experimental Methods}

\subsection{Description of the Rock Samples}

[13] Iron ore is an arenite with an average grain size of $0.2 \mathrm{~mm}$ (Figure 1a). The grains, called ooliths, are made of goethite (ferric oxide-hydroxide). Calcite, siderite, iron oxides and ferriferous phyllosillicates (berthierine), in varied proportions and compositions, cement these ooliths 

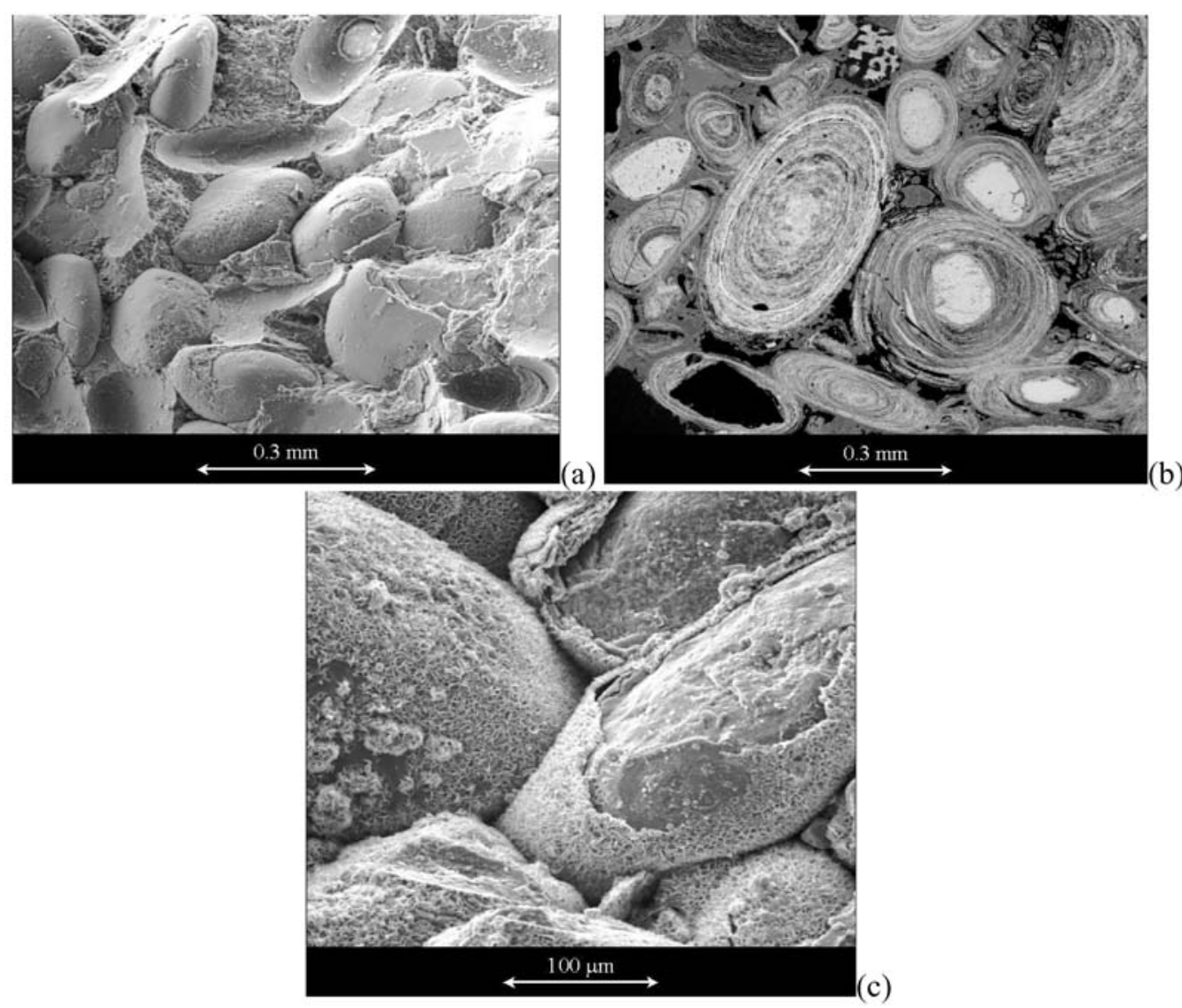

Figure 1. (a) Typical crack surface of "healthy" oolitic iron ore (SEM observation). (b) Example of iron ore textural organization. Cortexes are made up of concentric layers of goethite (SEM observation on polished section). (c) Typical crack surface of oolitic iron ore after aging in the mine. Interoolithic cement is completely weathered, and ooliths are encased by neoformed iron oxides.

[Dagallier et al., 2002]. Iron ore is a porous rock (30-35\%) with two kinds of pores: inter-oolithic and intra-oolithic. Indeed, intra-oolithic cortices, which are made up of concentric layers of goethite, are porous (Figure 1b). The entire porosity of iron ore is interconnected and the porous network, analyzed via a Purcell test (mercury intrusion porosimetry), is mainly composed of mesopores whose radii are between 0.001 and $0.03 \mu \mathrm{m}$ in size [Grgic et al., 2005].

\subsection{Description of the Hydromechanical Experiments}

[14] The hydromechanical device used in this study (Figure 2) is a hermetically sealed uniaxial compression cell in which samples can be subjected to saturated or partially saturated moisture conditions. Four cylindrical samples (of height $h=76 \mathrm{~mm}$ and diameter $\varphi=38 \mathrm{~mm}$ ) were tested in these cells and deformation was measured with strain gages. Samples A and B were tested for the study of subcritical stress corrosion cracking, and samples C and $\mathrm{D}$ were tested for the study of plastic deformations. All tests were performed in a room with well controlled temperature $\left(T=20 \pm 1^{\circ} \mathrm{C}\right)$. The use of uniaxial creep tests is justified because after excavation the stress state in mine pillars is uniaxial at the periphery and, at the center, the horizontal stress is not significant $(\sim 3.5 \mathrm{MPa})$.

\subsubsection{Samples A and B: Study of Subcritical Stress Corrosion Cracking}

[15] For partially saturated conditions, a salt solution was placed in a container at the base of each cell. The sample was then exposed to air in which the partial pressure of

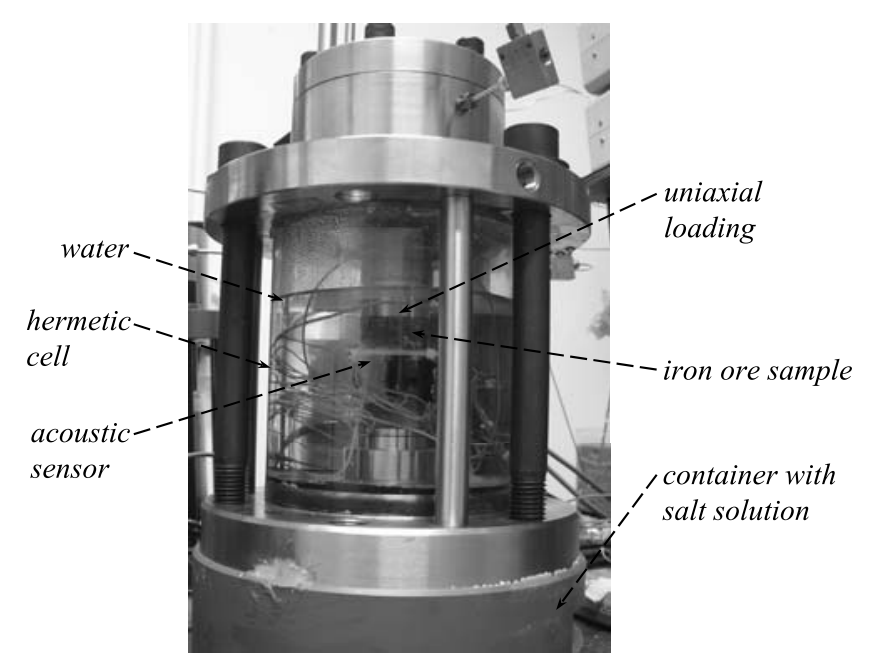

Figure 2. Hydromechanical device, uniaxial compressive cell (sample A). 
water vapor was imposed by the salt solution. In order to simulate the hydration history imposed on iron ore rocks in a mine, samples A and B were initially saturated, then dried in the hermetic cell, where the relative humidity imposed by the salt solution $\left(\mathrm{ZnSO}_{4} \bullet 7 \mathrm{H}_{2} \mathrm{O}\right)$ was equal to $90 \%$, i.e., a value measured in underground iron mines during mining workings. The corresponding value of capillary pressure is given by the Kelvin law (equation (1)): $p_{c}=14.2 \mathrm{MPa}$. If we consider the suction curve (relationship between the degree of saturation and capillary pressure) for iron ore [Grgic et al., 2005], it is possible to obtain the degree of saturation: $S_{l}=40 \%$.

[16] After equilibrium was obtained with the hydrous environment, a uniaxial, multistress step creep test was performed; the two samples A and B were exposed simultaneously to the same loading path (loading rate $=0.0067 \mathrm{MPa} /$ $\mathrm{sec})$. Multistep creep tests were performed in part because this kind of test saves a lot of laboratory time. Moreover this method permits us to apply many loads and obtain a large amount of data from a single sample without being confronted by repeatability problems due to material heterogeneity. Only sample A was equipped with acoustic sensors (see section 3.3) whereas the test on sample B was performed in order to verify the repeatability of the mechanical results.

[17] At the 4th stress level $\left(\sigma_{11}=11.4 \mathrm{MPa}\right.$, a value close to the vertical stress sustained by iron ore pillars in the mine), 106 days after the beginning of the experiment, samples are immersed in water (taken from the mine) that is chemically equilibrated with iron ore rock (in order to inhibit mineralogical transformations or dissolution) so as to simulate flooding conditions occurring when mining operations are stopped.

\subsubsection{Samples C, D, and E: Study of Viscoplastic Mechanisms}

[18] Samples C and D were tested under saturated conditions, and sample $\mathrm{E}$ was dried in a hermetic cell, where the relative humidity was equal to $0 \%$. Since the aim was to show that time-dependent inelasticity may also result from plastic deformation due to a dislocation creep mechanism, multistep creep tests with inverse loadings were performed on these samples. Samples C, D, and E were tested under uniaxial loading conditions, and samples D and E were equipped with acoustic sensors. The loading and unloading rates before each stress step were low $(0.0035 \mathrm{MPa} / \mathrm{s}$ for samples $\mathrm{C}$ and $\mathrm{E}$ and $0.000006 \mathrm{MPa} / \mathrm{s}$ for sample $\mathrm{D}$ ) in order to reduce significantly delayed elasticity effects and poroelastic effects due to flow of pore water out of and into the samples.

\subsection{Measurements of Acoustic Emissions: Samples A, $\mathbf{D}$, and $\mathbf{E}$}

[19] In order to track the AE induced by deformation, two sensors (nano30s, provided by Physical Acoustic Corporation - PAC, peak frequency $300 \mathrm{kHz}$, operating frequency range $175-750 \mathrm{kHz}$ ) were glued on samples $\mathrm{A}, \mathrm{D}$, and $\mathrm{E}$ using silicone gel and a ring which pressed the sensor onto the sample surface (Figure 2). The sensors were located on the middle part of the sample, diametrically opposed, and were connected to a $40-\mathrm{dB}$ preamplifier (PAC 1220) that included a band pass filter $(20-1200 \mathrm{kHz})$. Acoustic activity was monitored by a digital acquisition board
(PAC disp-4) plugged into a PC. The sampling frequency was $10 \mathrm{MHz}$ and the vertical resolution was 16 bits for a maximum signal amplitude of $\pm 10 \mathrm{~V}(96 \mathrm{~dB})$.

[20] During operation, the system continuously monitors the signal from the sensors. When a given amplitude threshold is reached, 4096 data points are recorded at $10 \mathrm{MHz}$, over a duration of $409.6 \mu \mathrm{s}$. For the experiment presented here, the trigger was set to $45 \mathrm{~dB}(45 \mathrm{mV})$. A ring buffer memory allows us to record a part of the signal before the trigger (10\% of the signal length). The maximum recording rate of the system is several hundred files per second. For each recorded signal, the maximum amplitude, energy and frequency contents are calculated. In addition, the system generates a pulse at each sensor, allowing the quality of the coupling of the sensors to the samples to be assessed. We were not able to measure the travel time of the pulse because the system suspends the amplification after the pulse emission for a duration longer than the travel time.

\section{Results}

\subsection{Deformation of Iron Ore Samples}

[21] Figure 3 shows the evolution of the axial, lateral and volumetric inelastic deformations, and of the inelastic distortion during the uniaxial multistep creep tests carried out on samples A and B. The deformations which occurred during initial loadings have not been shown. Failure of sample B occurred 17 days after immersion in water for $\sigma_{11}=11.4 \mathrm{MPa}$, and the total time to failure (from the beginning of the experiment) was 124 days. The failure of sample A was not obtained within 66 days after immersion in water for $\sigma_{11}=11.4 \mathrm{MPa}$; therefore, the stress level was increased to $12.3 \mathrm{MPa}$ and failure was obtained 22 days later and the time to failure $t_{f}$ (from the beginning of the experiment) was 195 days. The recorded strains of samples A and B are shown only over 140 and 118 days, respectively, because the development of cracks and strain localization in the sample rendered the strain gages unusable. At the beginning of each stress level, an unloading-reloading cycle was performed in order to determine the drained elastic moduli ( $E_{o}$, the drained Young's modulus, and $\nu_{o}$, the drained Poisson's ratio). Both total $(\sigma)$ and effective $\left(\sigma^{\prime}\right)$ stresses are indicated in Figure 3 (see section 5.2.). Figure 4 shows the evolution of these moduli for sample $\mathrm{A}$, the sample fitted with acoustic sensors.

[22] Figures 5, 6, and 7 show the evolution of the axial, lateral and volumetric inelastic deformations, and of the inelastic distortion during the multistep creep tests on samples C, D, and E, respectively. The total strains (elastic + inelastic) have also been shown for sample D.

\subsection{Associated Acoustic Emissions: Samples A, D, and E}

[23] As the trigger mode we used was only based on amplitude, we checked all the recorded signals to ensure that they originated from sample deformation and not from electronic noise. We extracted those events corresponding to electronic noise from the catalog (mainly dirac-like signals displaying short risetime and duration, an absence of coda, and a single peak frequency). Figure 8 represents the cumulative number of $\mathrm{AE}$ events during the multistep creep test on sample $\mathrm{A}$, including the last stress level $\left(\sigma_{11}=12.3 \mathrm{MPa}\right)$ for which strains could not be measured. The file into which 


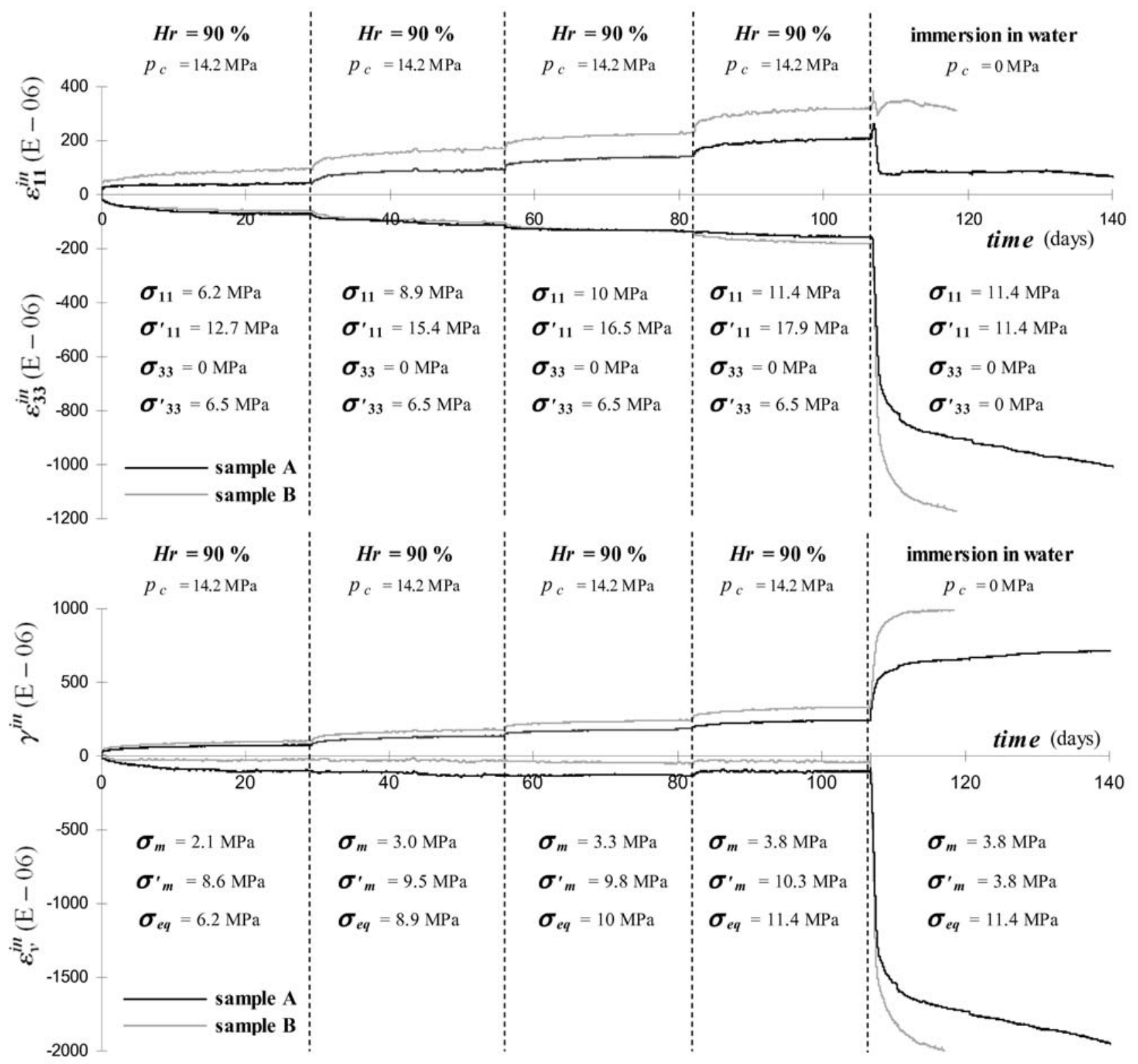

Figure 3. Evolution of the axial, lateral, and volumetric inelastic strains and the inelastic distortion with time in uniaxial multistep creep tests on samples A and B.

event data from day 160 to day 180 were recorded has unfortunately not been saved by the computer. The inelastic volumetric strain is also shown in Figure 8. (Figures 11 and 12 show the cumulative number of $\mathrm{AE}$ events during the multistep creep test on samples D and E.)

[24] We studied the statistical distribution of the $\mathrm{AE}$ energy, which is estimated with

$$
E_{A E}=\sum_{t_{1}}^{t_{2}} A^{2}(t) \Delta t
$$

where $A$ is the amplitude of the AE signal, $t_{1}$ and $t_{2}$ are the time of the beginning and the end of the recorded signal, and $\Delta t$ is the sampling interval. Energy is calculated in arbitrary units.
[25] We calculated the cumulative distribution function (cdf) and the probability density function (pdf) of the energy (Figure 9). These analyses show the population distribution of events for each step of the creep test. For the first steps of the creep test, corresponding to $h_{r}=90 \%$, the pdf appears to be flat in the range $0.1<E_{A E}<10$ which is due to the incomplete nature of the catalog for smaller events. For the last two steps, 5 and 6, i.e., in the saturated domain, the distribution displays power law behavior over 2 and 4 decades, respectively,

$$
p\left(E_{A E}\right) \sim E_{A E}^{-b}
$$

Equation (6) is comparable to the empirical GutenbergRichter law for earthquakes [Gutenberg and Richter, 1954]. Indeed, many authors [e.g., Mlakar et al., 1993; Ohnaka 


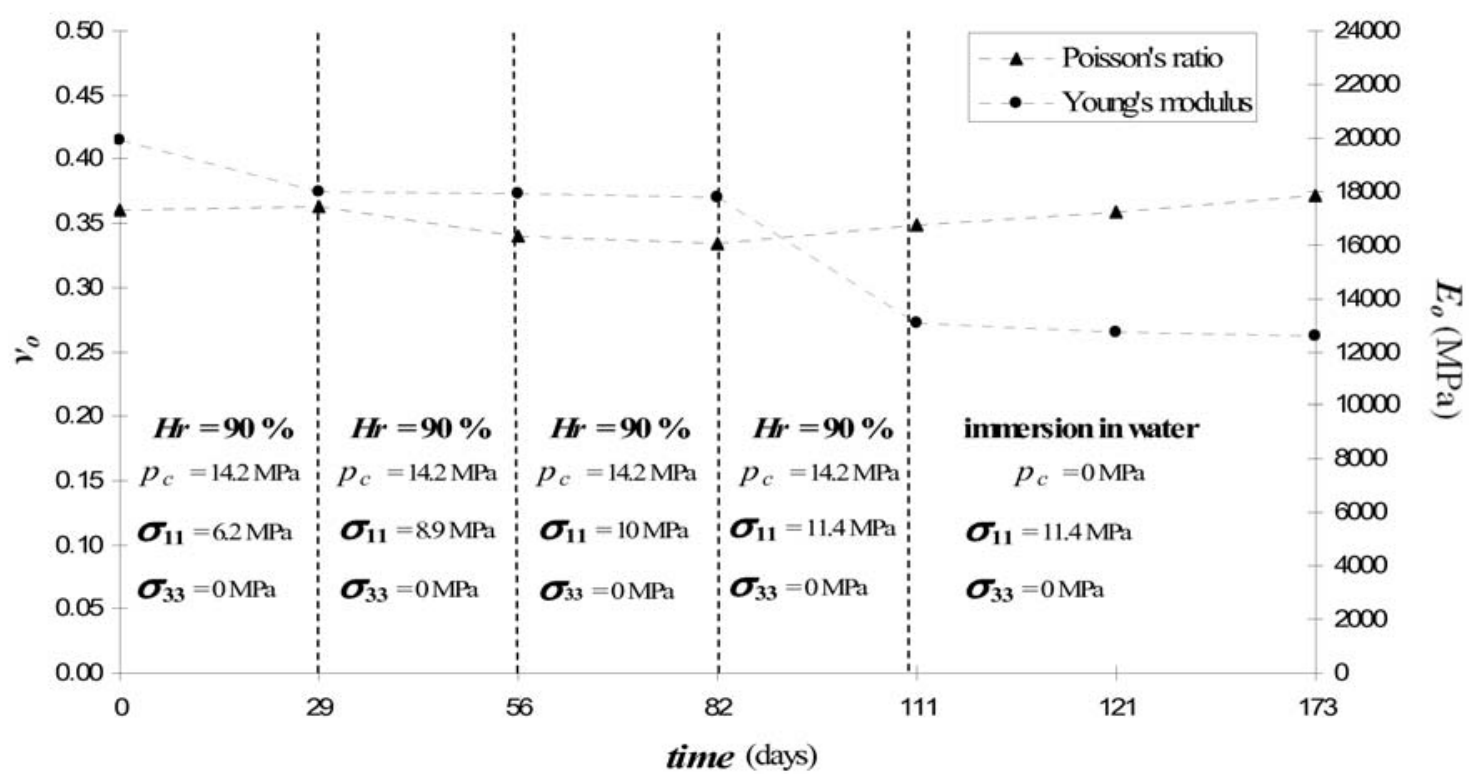

Figure 4. Evolution of the drained elastic moduli ( $E_{\mathrm{o}}$, drained Young's modulus; $\nu_{\mathrm{o}}$, drained Poisson's ratio) in the uniaxial multistep creep test on sample A.

and Mogi, 1982; Scholz, 1968b] have shown that the distribution between AE frequency and amplitude or energy displays one or more logarithmically straight lines with a negative slope. The absolute value of this slope is called the $b$ value. Our calculated $b$ value for energy distribution is twice that calculated for amplitude or for magnitude. The $\log -\log$ plot of the cumulative number of AE events $\left(N_{A E}\right)$ versus energy has been represented in Figure 10 for different values of time $(t)$ normalized by the time to failure $\left(t_{f}\right)$. Only the range $10<E_{A E}<10^{8}$ corresponding to a power law trend has been represented. Figure 10 also shows the evolution of the $b$ value as a function of $t / t_{f}$. For $t / t_{f} \leq 0.9$, i.e., just before the stage of accelerated creep, $b \sim 1.2$ and for $t / t_{f}>0.9, b \sim 0.4$.

\section{Discussion}

5.1. Viscoplastic Deformation of Iron Ore: Samples C, $D$, and $\mathbf{E}$

[26] According to the microscopic theory of plasticity, plastic deformation occurs via the motion of defects of the crystal lattice. These defects are points defects, dislocations (linear defects) and two-dimensional defects (grain and twin boundaries, slip bands, etc.). The migration of dislocations by slip and/or climb under the action of an applied stress forms the basic mechanism of plastic flow in solids. Dislocation climb is precluded by the low temperature in our creep tests $\left(\sim 20^{\circ} \mathrm{C}\right)$ and in underground iron mines $\left(\sim 13^{\circ} \mathrm{C}\right)$. This is also the case for many other creep mechanisms, such as diffusion creep, twinning and grain boundary sliding, which are very significant at high temperatures in polycrystalline carbonate materials [Renner et al., 2002; Kennedy and White, 2001; Newman and Mitra, 1994]. In this section we shall concentrate only on a dislocation creep mechanism.

[27] Dislocations are set in motion by the externally applied load in the direction of that load [Beeman and Kohlstedt, 1988; Boyko et al., 1994] and motion occurs if the external load exceeds the drag (or resistance) stress on dislocations. According to the concept originally proposed by Bailey [1926] and Orowan [1946], creep straining results from the combined but competitive action of hardening and recovery mechanisms. Strain hardening is related to immobilization and piling up of dislocations at barriers and causes an increase in dislocation density and internal stress. It is the main mechanism in the primary stage of creep and, therefore, is responsible for the decrease in creep rate in this transient stage. Barriers to dislocation motion imply that continued plastic straining requires an increased applied stress or recovery. Recovery is a process by which deformed crystals reduce their stored energy (i.e., internal stress) by the escape of dislocations from their glide planes to annihilation sites via slip and climb, thereby reducing the dislocation density. The main differences between slip and climb are that slip has a comparatively small dependence on temperature and is caused primarily by shear stress, whereas climb occurs much more rapidly at high temperatures due to the increase in required vacancy motion at high temperatures. In metal alloys, ice and ductile rocks like rock salt, the equilibrium between strain hardening and recovery is established during the secondary stage of the creep process.

[28] Reversible creep can correspond physically to the reversible motion of dislocations between strong obstacles. However, after stress removal, the forces of interaction between dislocations are usually insufficient to overcome the drag stress [Boyko et al., 1994]. Hence, the drag stress is the reason for the incomplete reversibility of the motion of dislocations. For metal alloys, many physical processes can explain reversible plasticity [Boyko et al., 1994; Natsik et al., 2003]: elastic twinning, athermal superelasticity (due to a phase transformation) and thermally activated shape memory effects.

[29] The uniaxial creep test on sample C (Figure 5) shows that the inelastic axial strain decreases integrally when the stress is removed. The axial strain is totally recovered after reloading and decreases again after the second stress 


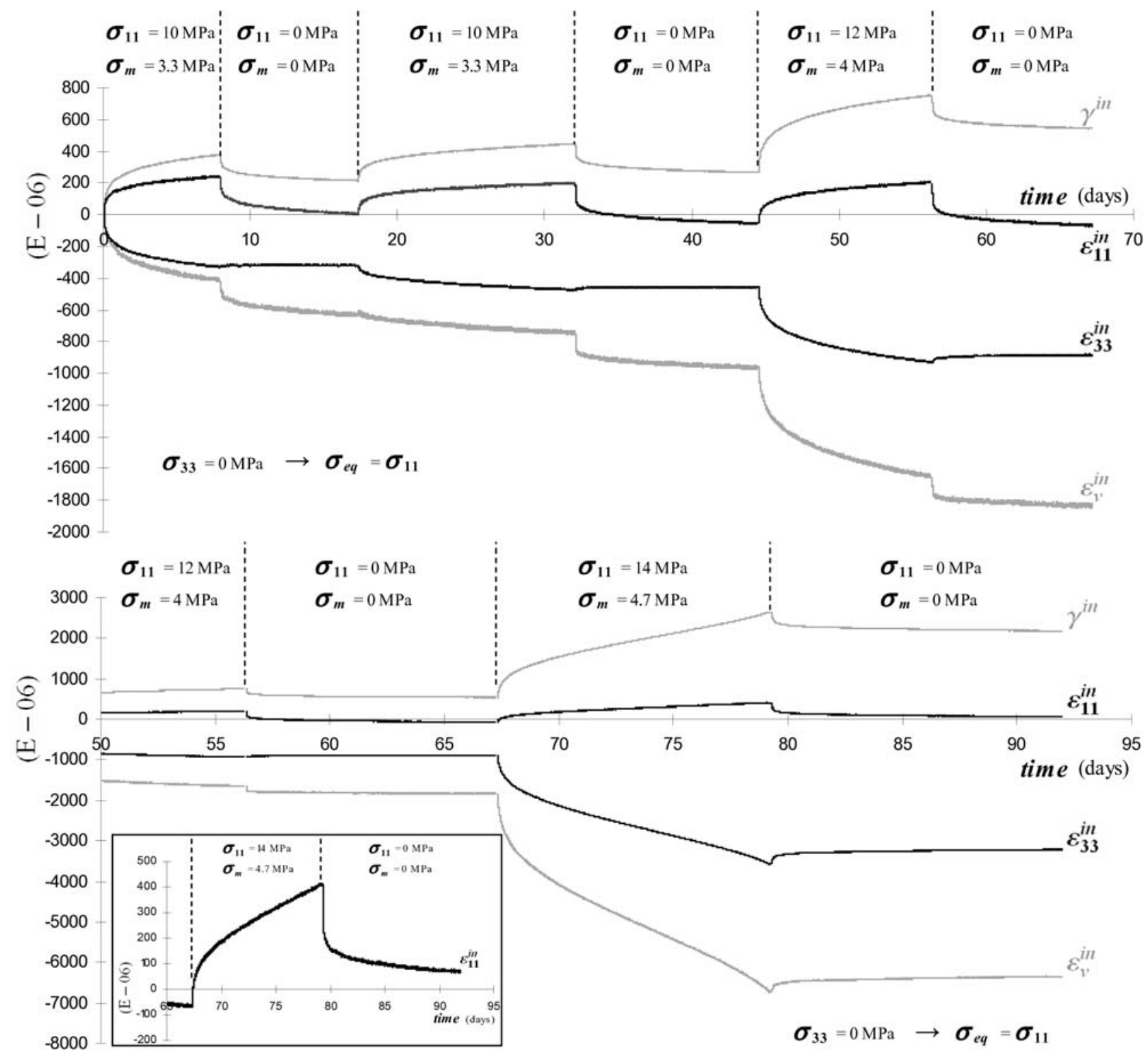

Figure 5. Evolution of the axial, lateral, and volumetric inelastic strains and the inelastic distortion with time in the uniaxial multistep creep test on sample $C$ (saturated conditions). Insert is a zoom of the axial inelastic strain during the two last steps.

removal. The axial is totally reversible up until $\sigma_{11}=12 \mathrm{MPa}$. Below this stress level, immobilization and piling up of dislocations during forward straining causes the creep rate to decrease and therefore leads to strain hardening and primary (transient) creep. The backward straining resembles that of the forward straining indicating that the same plastic deformation mechanism is implied in both cases. The full reversibility of the axial strain highlights the reversible motion of dislocations in the direction of the applied axial stress and, thereby, the low value of the drag stress in a rock like iron ore. The increase in the inelastic radial strain (Figure 5), which is almost irreversible and likely reflects the growth of axial (i.e., parallel to the direction of the maximum applied stress) tensile (or wing) cracks [NematNasser and Obata, 1988; Martin and Chandler, 1994], is responsible for the dilation of the rock (see section 5.3.).
This indicates that the irreversible damage mechanism contributes also to the rock deformation even at the lower stress levels (i.e., below $\sigma_{11}=12 \mathrm{MPa}$ ) at which only a primary (transient) phase of creep is observed.

[30] If the stress is high enough (i.e., $\sigma_{11}=14 \mathrm{MPa}$ ), the transient phase of creep is followed by steady state creep. In materials undergoing only dislocation creep, the applied stress must just be equal to the internal stress during the steady state stage and the dislocation density changes from its initial value to a constant value determined by the applied stress level. This dependence of dislocation density on the applied differential stress has been experimentally determined for many metals, calcite materials [De Bresser, 1996] and rock salt [Beeman and Kohlstedt, 1988]. In iron ore, both viscoplastic and brittle mechanisms are responsible for the creep deformation. Indeed, after a certain period 

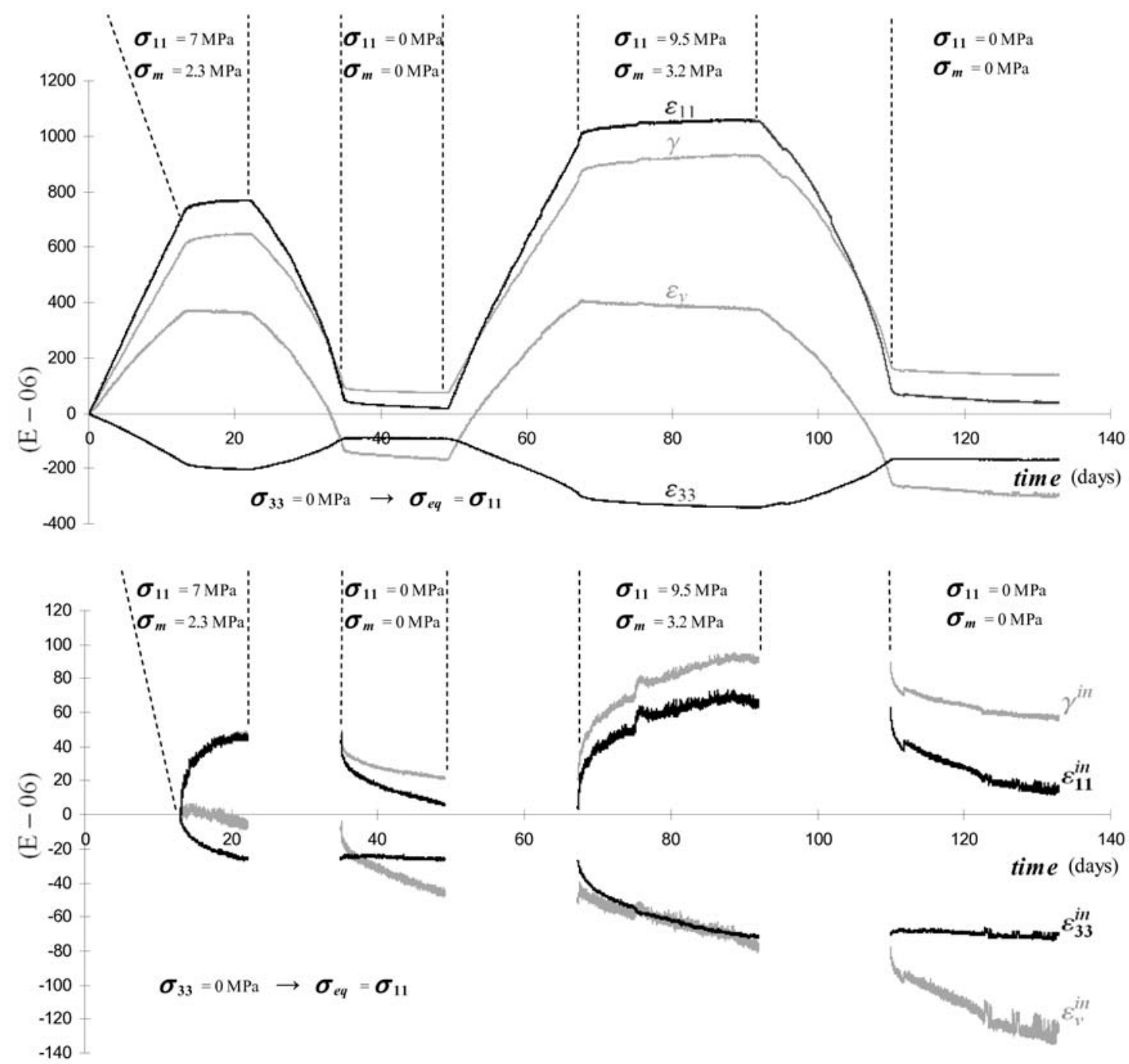

Figure 6. Evolution of the axial, lateral, and volumetric strains and the distortion with time in the uniaxial multistep creep test on sample D (saturated conditions).

of time (for $\sigma_{11}=14 \mathrm{MPa}$ ), secondary (steady state) creep is followed by tertiary (accelerated) creep (observable in the radial strain curve), indicating that time-dependent cracking plays the major role in the material deformation during these two stages. The axial strain is not entirely reversible after stress removal, only the fraction of strain due to plastic mechanism is reversible, indicating that both plastic and damage mechanisms are responsible for the creep deformation (the backward radial strain remains very small even for this high stress level). This also suggests that shear cracks have developed in the direction of the applied axial stress. Indeed, as observed by Lin et al. [2004] for granite, inelastic distortion increases in a linear manner with the inelastic volumetric strain indicating that tensile (wing) cracks and shear cracks develop at the same time. The irreversible fraction of inelastic axial strain is due to sliding along inclined crack surfaces. Since tertiary (accelerated) creep, which indicates the unstable propagation of microcracks, was reached just before unloading, the failure of the sample was obtained just after reloading at $\sigma_{11}=14 \mathrm{MPa}$.

[31] From a physical point of view, polycrystalline materials like iron ore deform plastically in an inhomogeneous way and generate two kinds of dislocations which contribute to the internal stress. Gradients of deformation build up within grains, requiring dislocations, called "geometrically necessary dislocations," to accommodate them [Ashby, 1971; De Bresser, 1996]. These dislocations are concentrated in grain boundary regions. In addition, "statistically stored dislocations" that are not geometrically needed are generated, mainly within grains, and achieve the general strain [Ashby, 1971; De Bresser, 1996]. The motion of these dislocations (via slip) is responsible for the inelastic axial strain during the first steps of the uniaxial creep tests (i.e., below $\sigma_{11}=14 \mathrm{MPa}$ ).

[32] Dynamic recrystallization, which is driven by strain energy and therefore occurs only during deformation, has been suggested as a dislocation creep accommodation mechanisms that leads to steady state flow [Dell'Angelo and Olgaard, 1995; Zeuch, 1982]. It is active at conditions where climb is inhibited (i.e., low temperature) and leads to a reduction in average dislocation density (and generally results in a reduction in grain size). It is worth emphasizing that water can promote dynamic recrystallization by fluidassisted grain boundary migration in rock salt undergoing 


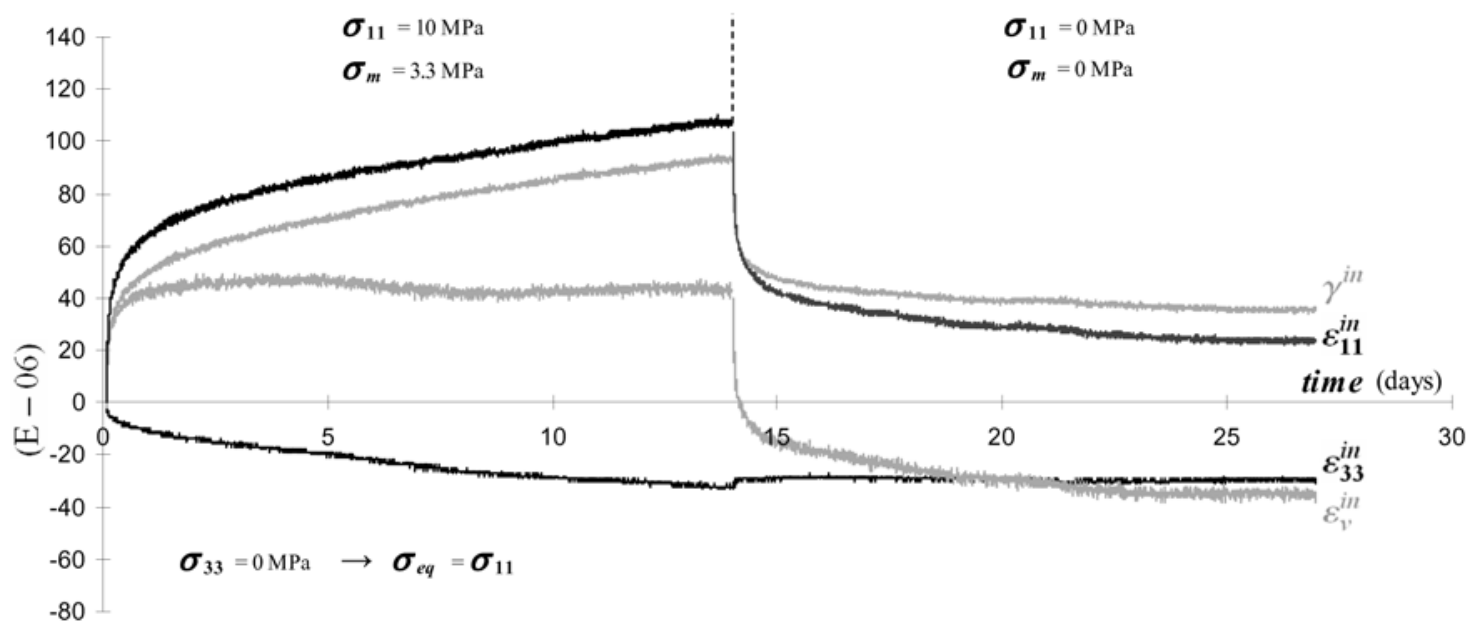

Figure 7. Evolution of the axial, lateral, and volumetric inelastic strains and the inelastic distortion with time in the uniaxial multistep creep test on sample E (dry conditions; $h_{r}=0 \%$ ).

dislocation creep [Ter Heege et al., 2005; Urai et al., 1986]. Indeed, fluids enhance the mobility and climb of defects, resulting in the same effect that an increase in temperature might have [Newman and Mitra, 1994]. In iron ore, calcite [Kennedy and White, 2001] and siderite could undergo dynamic recrystallization. However, at temperatures relevant to engineering conditions $\left(T \sim 13^{\circ} \mathrm{C}\right.$ in underground iron mines), this mechanism is precluded in carbonate minerals [Newman and Mitra, 1994; Kennedy and Logan, 1998]. Dynamic recovery is also a dislocation creep accom- modation mechanisms that can lead to steady state flow [Dell'Angelo and Olgaard, 1995]; dislocations are eliminated at grain boundaries or organize into subgrain boundaries. Since climb also cannot relieve dislocation pileups at grain boundaries (because of the low temperature in our case), high pileup stresses (i.e., for $\sigma_{11}=14 \mathrm{MPa}$ in our case) might reach the critical values necessary to generate boundary cracks [Renner et al., 2002]. Hence, further axial straining is accommodated by brittle fracturing, generating shear microcracks.

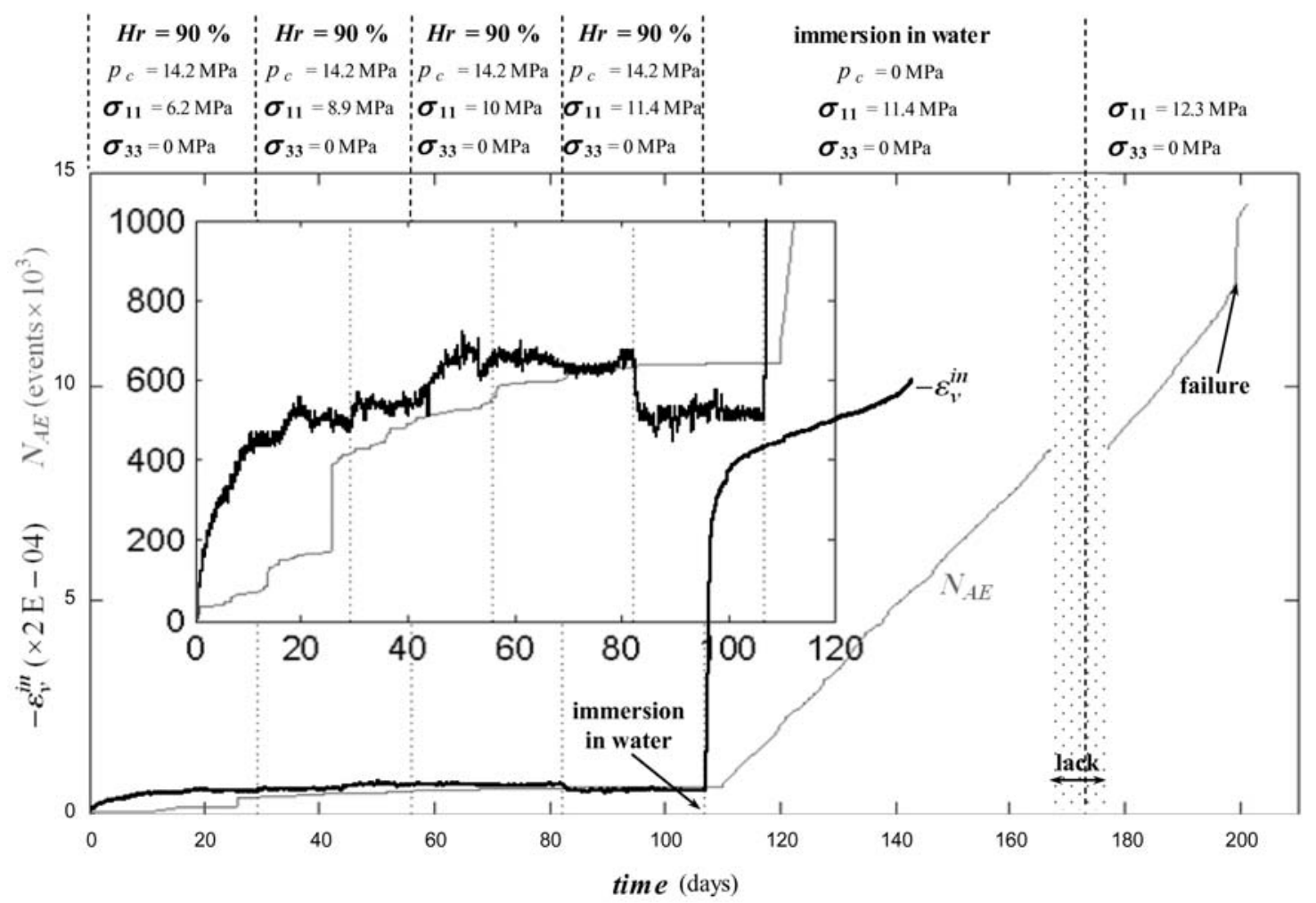

Figure 8. Cumulative number of $\mathrm{AE}$ events versus time in the multistep creep test on sample A (inelastic volumetric strain is also represented). Insert is a zoom of the initial part of the curve. 

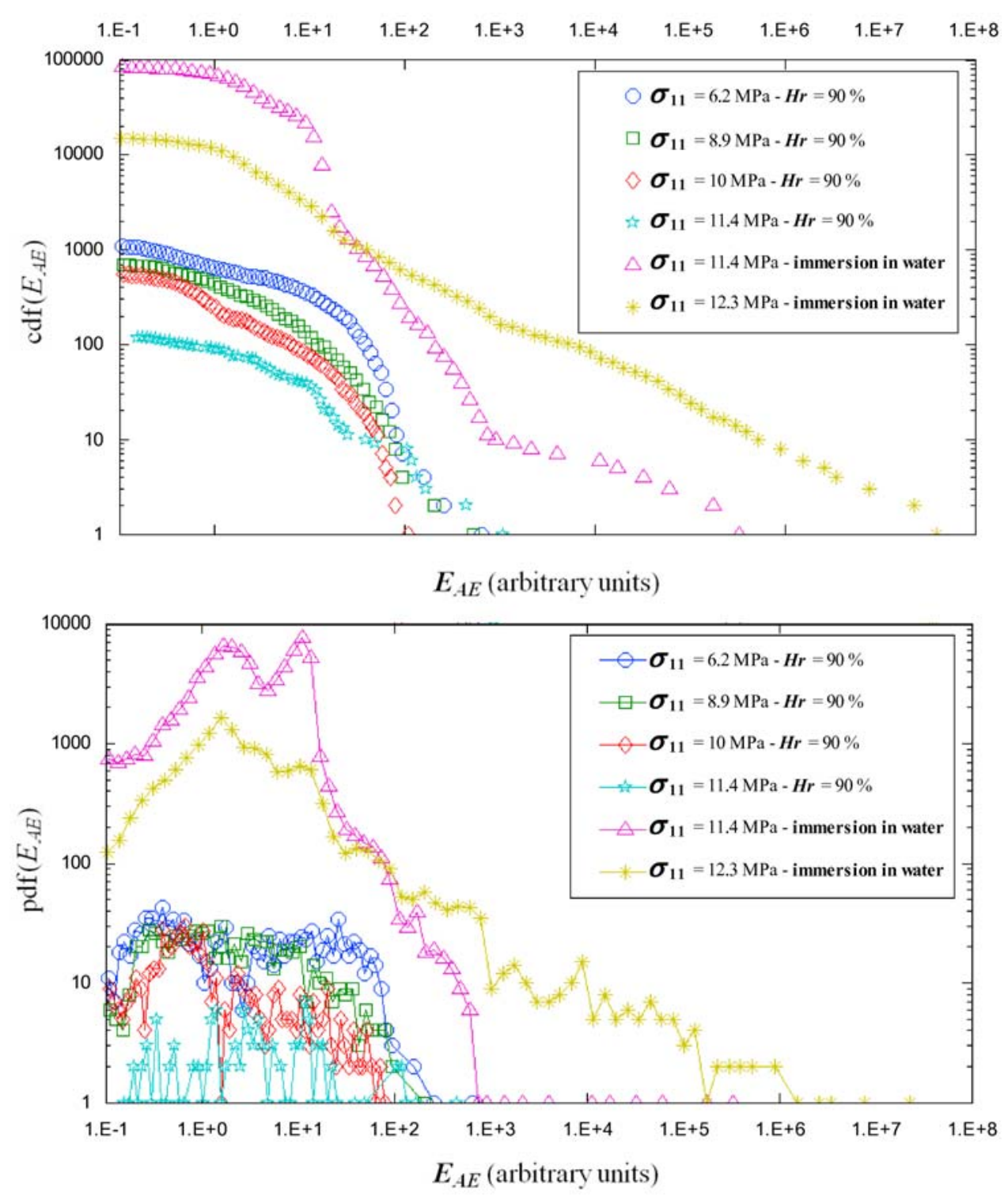

Figure 9. Cumulative distribution function (cdf) and probability density function (pdf) of the energy for each level of the multistep creep test on sample A.

[33] The reversibility of the viscoplastic deformation is also observable on the stress-strain curves obtained from the uniaxial multistep creep test on sample D (Figure 6). In this test, the loading and unloading rates are very low $(0.000006 \mathrm{MPa} / \mathrm{s})$, therefore a large fraction of the inelastic strain is produced during the loading and unloading phases. Figure 10 shows that the AE activity is much more important during the forward inelastic deformation than during the backward inelastic deformation. During forward straining, AE activity is mainly generated by microcracks, and AE events are primarily of small amplitude (and energy) compared to those obtained from the onset of accelerated creep leading to failure (see below, section 5.3.). During reverse straining, the number of AE events increases slightly, indicating that the ("forward" or "backward") motion of many interacting dislocations can induce $\mathrm{AE}$, as is observed in crystalline materials like ice single crystals [Miguel et al., 2001; Weiss et al., 2001] and metal alloys [Boyko et al., 1994; Dul'kin et al., 1997]. In addition, the energy of AE events, due to the motion of dislocations (during the backward stage), is much smaller than the energy induced by microcracks.

[34] Under triaxial conditions, the mechanical behavior of iron ore is slightly different from that observed under uniaxial conditions. Many short-term loading tests and creep tests, performed on iron ore in our laboratory, have shown that the strength, onset of dilatancy and time to failure increase due to the action of the confining pressure; the confining pressure suppresses the opening and propagation of microcracks and, therefore, increases the ductility of the rock. In addition, the reversibility of the inelastic axial strain was also observed during a triaxial creep test (not presented here), indicating that the mechanisms responsible for the material deformation, i.e., plasticity and microcracking, remain the same.

[35] Many authors [e.g., Scholz, 1968a, 1972] have reported that there is no evidence for inelastic intracrystalline deformation in silicate rocks and ceramic materials 

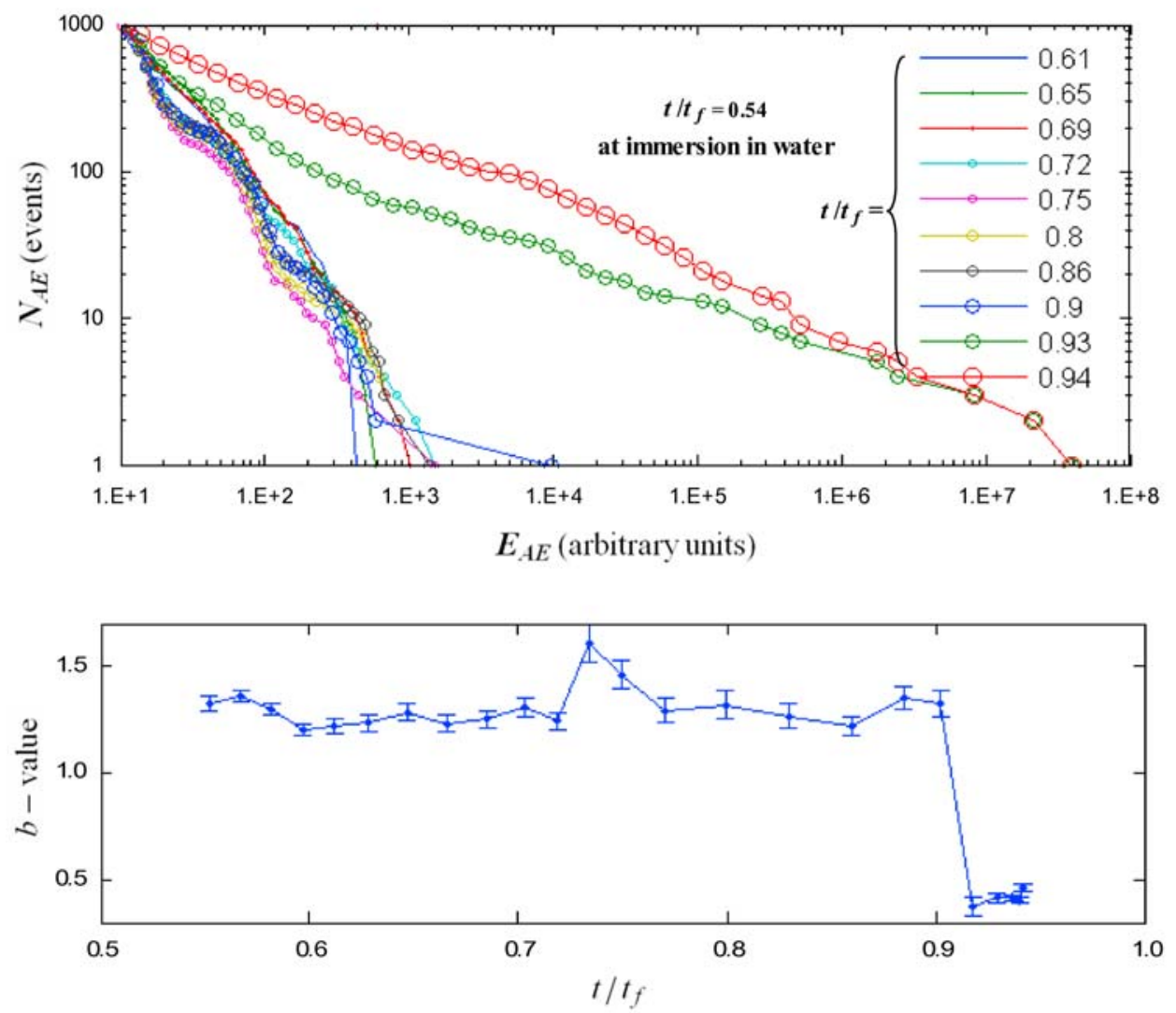

Figure 10. Cumulative number of $\mathrm{AE}$ events versus signal energy and evolution of the $b$ value versus $t / t_{f}$ in the saturated domain (sample A).

deformed at low temperatures and pressure in the brittle fracture regime. However, low-temperature dislocation creep is of major importance in rock salt [Beeman and Kohlstedt, 1988; Urai and Spiers, 2007] and has been documented [Barber and Wenk, 1979] just above room temperature in calcite rocks. We have suggested that in a porous polycrystalline rock like iron ore, a fraction of the inelastic deformation is due to plastic deformation of one or more of the constituent phases, even at low temperature and confining pressure. To justify this statement, we propose the following arguments.

[36] First, it is worth emphasizing that only primary creep, due to strain hardening, is observed during our creep tests and steady state creep, during which the equilibrium between strain hardening and recovery is established, is never observed. Indeed, there are many small regions of stress concentration in rocks (at grain and phase boundaries and at tips of microcracks and pores) where the local stress may be much larger than the applied stress and overcome the resistance to glide of dislocations, thus increasing the viscoplastic strain, even though the temperature is low during our creep tests. Indeed, as stated above, slip has only a small dependence on temperature and is caused by only shear stress. In contrast to most other rock forming minerals, calcite deforms plastically at room temperature provided that cleavage fracture is suppressed [Barber and Wenk, 1979]. Barber and Wenk [1979] also stated that at low temperatures, plastic deformation occurs by movement of dislocations on glide planes (conservative motion). At higher temperatures, dislocations can move off their glide planes and climb, which is not the case in our experiments; the strain rate decreases because of immobilization and piling up of dislocations at barriers. In iron ore, interoolithic calcite, dolomite and siderite could undergo viscoplastic deformation.

[37] Second, the "forward" and "backward" mobility of dislocations in this rock tested at room temperature and without confining pressure could be favored by the presence of fluids. Indeed, in carbonate rocks (e.g., dolomite, limestone), the presence of water (i.e., a polar fluid) in the calcite crystal structure may enhance the mobility of dislocations, even though there is to date no experimental evidence [Newman and Mitra, 1994; Kennedy and Logan, 1998]. Indeed, incorporation of water into a crystal structure will introduce charged point defects in the crystal which should enhance the mobility of dislocations [Kennedy and Logan, 1998; Rutter, 1974]. Rehbinder and Lichtman [1957] attributed the weakening of single crystals by the action of water to a reduction of interfacial tension and suggested that this reduces the work hardening component due to the pileup of dislocations at the crystal-fluid interface, and increases the probability of emergence of dislocations onto the crystal surface. These effects of water are termed "Rehbinder effects." Moreover, as noticed by Rutter [1972], the weakening effect of water through action at grain boundaries is likely to be greatest in rocks of high porosity and small grain size (like iron ore) in which a large surface area will be exposed to the pore fluid. Rutter [1974] 


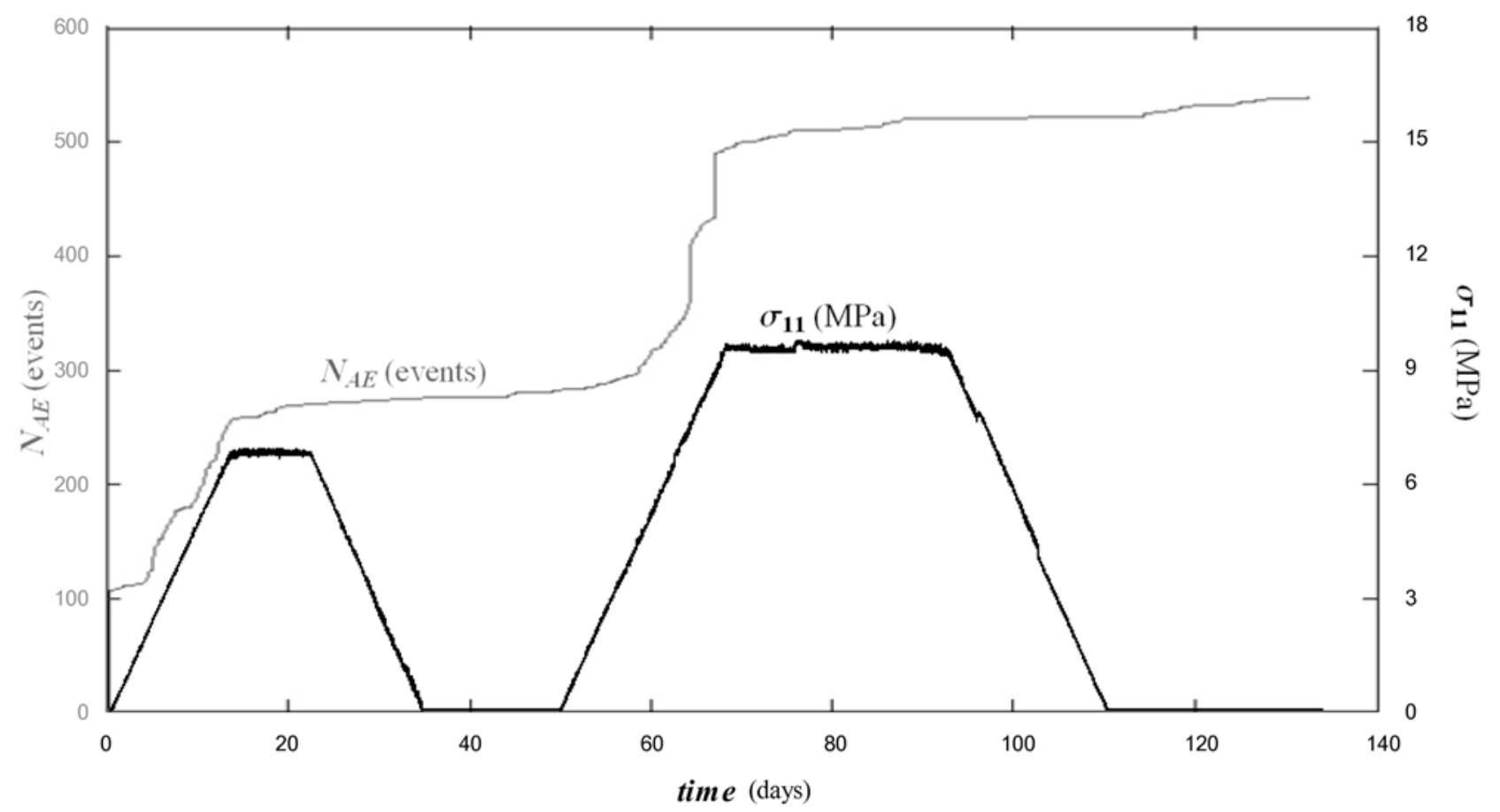

Figure 11. Cumulative number of $\mathrm{AE}$ events versus time in the multistep creep test on sample D (the uniaxial stress $\sigma_{11}$ is also represented).

emphasizes also that according to experimental data, Rehbinder effects become insignificant at high temperatures, even in a fine-grained limestone. This could be explained by the increased mobility of point defects at elevated temperatures that would eventually override Rehbinder effects. In our experiments, performed at room temperature, Rehbinder effects are not overridden by the temperature and are probably of great importance. Therefore, we can suppose a decrease in the activation energy, used as a parameter in many creep laws (e.g., Peierls law [Renner et al., 2002], power law), due to the action of water at low temperature. In addition, cracks provide fluid paths, increasing rock-fluid interaction, and generate numerous dislocations. The infiltration of fluids into deformed grains or crystal lattices may enhance the mobility of dislocations (and therefore the recovery of strain-hardened rocks). This hydrolytic weakening may result in low-temperature viscoplasticity which accommodates microcracking processes [Liu et al., 2002].

[38] For all these reasons, plastic deformation of iron ore probably occurs during our creep tests. The reversibility of the axial creep deformation can only be explained by the reversible motion of dislocations in the direction of the applied axial stress, as stated above. This is not due neither to the delayed elasticity effect nor to a poroelastic effect due to flow of pore water out of and into samples. Indeed, as stated in section 3.2., the loading and unloading rates before each stress step have been chosen to be sufficiently low to inhibit such effects. Iron ore is a very porous rock and the intrinsic permeability is relatively high $\left(10^{-18} \mathrm{~m}^{2}\right)$ to ensure a good drainage of the interstitial water. In addition, pore pressure is by nature hydrostatic (or isotropic); therefore its variations could not explain the reversibility of only the axial creep strain.
[39] The multistep creep test performed on sample E under dry conditions (i.e., without interstitial water) shows also the reversibility of the inelastic axial strain after stress removal (Figure 7), illustrating the reversible motion of dislocations even without water. However, unlike for sample C (Figure 5), the axial strain is not totally recovered. This could be explained by the absence of Rehbinder effects [Rehbinder and Lichtman, 1957], which enhance the mobility of dislocations, as suggested above. Under dry conditions, the forces of interaction between dislocations are perhaps insufficient to overcome the drag stress after stress removal, explaining thus the incomplete reversibility of the motion of dislocations. The deformation of iron ore is less significant under dry conditions (Figure 7) than under saturated conditions (Figure 5). Indeed, as explained below (section 5.2.), under unsaturated conditions, the capillary attraction forces harden rocks since they induce an increase in the effective mean stress. This is equivalent to the application of a confining pressure; the material exhibits therefore a contractant behavior (the inelastic volumetric strain is positive) whereas the behavior is dilatant under saturated conditions. As for sample D (Figure 11), the AE activity of sample E (Figure 12) during forward straining is mainly generated by microcracks. However, the backward motion of dislocations, which probably explain the reversibility of the inelastic axial strain, does not induce AE, maybe because the amplitude of the events is not high enough to exceed the trigger level (45 dB).

\subsection{Mechanical Influence of Water Pressure: Hydromechanical Coupling}

[40] Pore fluids influence first the time-dependent deformation and strength of porous rocks like iron ore through hydromechanical coupling, which is formulated via the 


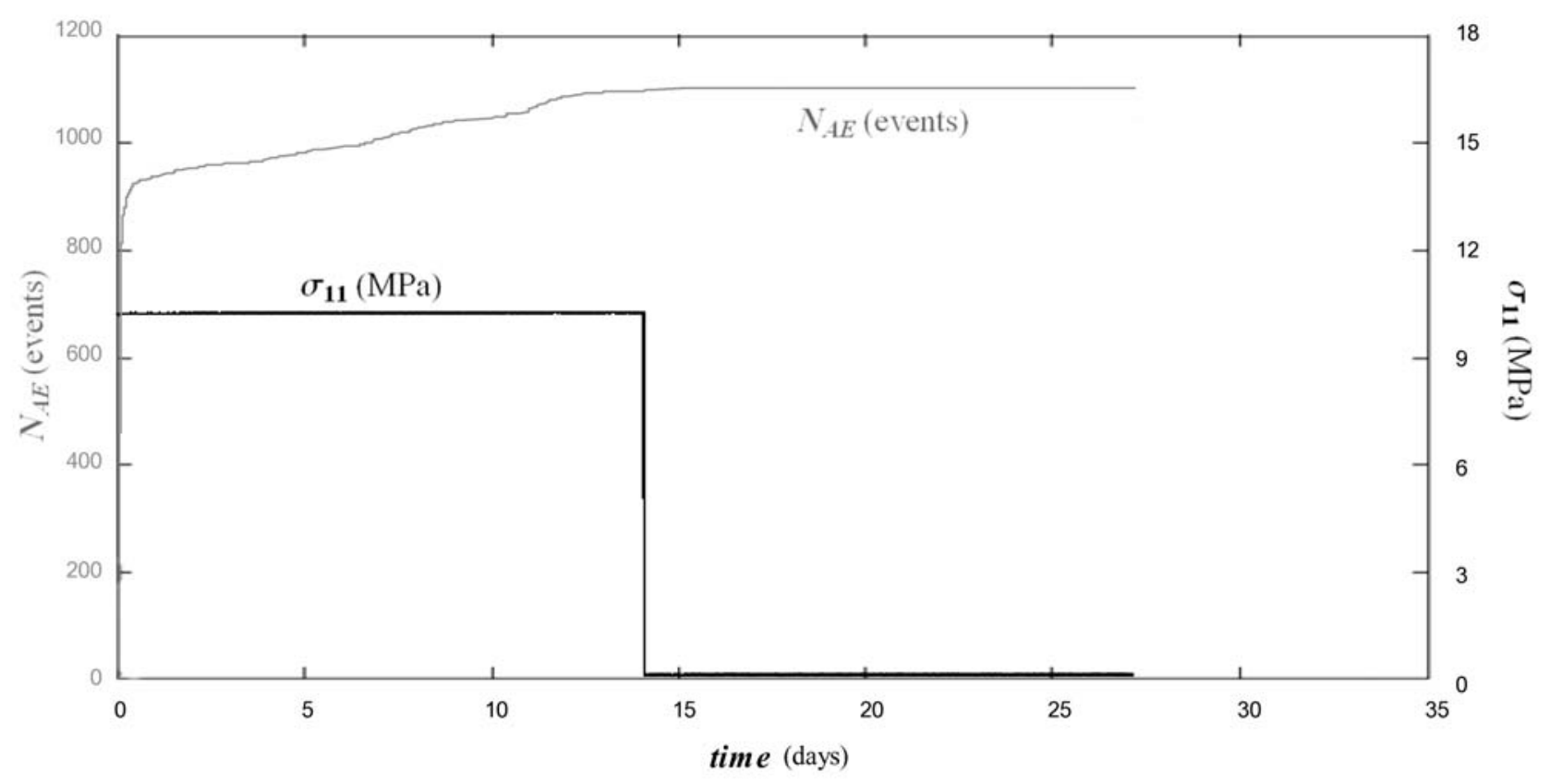

Figure 12. Cumulative number of $\mathrm{AE}$ events versus time in the multistep creep test on sample $\mathrm{E}$ (the uniaxial stress $\sigma_{11}$ is also represented).

effective stress concept. The effective stress, from a physical point of view, corresponds to the stress that is effectively exerted on the solid skeleton and that is therefore responsible for the deformation of the porous material. The total stress tensor may be decomposed into an effective stress tensor and a pressure tensor:

$$
\underline{\underline{\sigma}}=\underline{\underline{\sigma^{\prime}}}+\sigma_{p} \underline{\underline{1}}
$$

For isotropic elastic behavior, the equation of the effective stress tensor is written as a function of elastic parameters obtained under drained conditions (i.e., without pore pressure variation):

$$
\underline{\underline{\sigma}}^{\prime}=\frac{E_{o} \nu_{o}}{\left(1+\nu_{o}\right)\left(1-2 \nu_{o}\right)} \varepsilon_{\nu} \underline{\underline{1}}+\frac{E_{o}}{1+\nu_{o}} \underline{\underline{\varepsilon}}
$$

where $\varepsilon_{v}, E_{o}$ and $\nu_{o}$ denote the total volumetric strain, the drained Young's modulus and the drained Poisson's ratio, respectively.

[41] Many theories have been developed in order to propose a representation of the fluid pressure tensor $\sigma_{p}$. The theory developed by Coussy [1995] for partially saturated porous media appears to be particularly relevant for iron ore [Grgic et al., 2005]. In this theory, Coussy introduced a $\pi$ function, which represents the equivalent interstitial pressure, and the partitions of the elastic stress tensor and the elastic mean stress for partially saturated porous media are written as follows:

$$
\sigma_{p}=B \pi \quad \underline{\underline{\sigma^{\prime}}}=\underline{\underline{\sigma}}-B \pi \underline{\underline{1}} \quad \sigma_{m}^{\prime}=\sigma_{m}-B \pi
$$

where $B$ is the Biot coefficient ( $B=0.9$ for iron ore).

[42] The $\pi$ function proposed by Coussy [1995] takes into account in its formulation both fluid pressure (i.e., $S_{l} p_{c}$ ) and interfacial (air/liquid water) tension (i.e., the last term in equation (10)):

$$
\pi=p_{g}-\int_{0}^{p_{c}} S_{l}(x) d x=p_{g}-S_{l} p_{c}-\int_{S_{l}}^{l} p_{c}(x) d x
$$

where $S_{l}$ and $p_{g}$ denote the liquid saturation and the gas (water vapor and dry air) pressure, respectively.

[43] This function allows the generalization of the pore pressure in both saturated and partially saturated cases: $\pi$ is equal to the liquid pressure in the saturated domain $\left(\pi=p_{l}\right.$ when $\left.S_{l}=1\right)$ and is negative in the partially saturated domain ( $\pi<0$ when $\left.S_{l}<1\right)$. It is calculated from sorption curves (liquid saturation versus capillary pressure) for both adsorption and desorption paths. For iron ore, and for a desorption path corresponding to a decrease of the relative humidity $h_{r}$ from $100 \%$ to $90 \%$ (i.e., $p_{c}$ increases from 0 to 14.2 MPa), $\pi$ is equal to $-7.3 \mathrm{MPa}$ [Grgic et al., 2005]. The influence of pore fluids, through hydromechanical coupling, on the time-dependent deformation of porous rocks is often described in literature [e.g., Sammonds et al., 1995; Baud and Meredith, 1997] but rarely with the equivalent interstitial pressure $\pi$ in mind.

[44] Figure 13 shows, in the space of effective stress invariants $\left(\sigma_{m}^{\prime}, \sigma_{e q}\right)$, the failure and dilatancy surfaces of iron ore, obtained from short-term (i.e., "instantaneous") triaxial compressive tests in both partially saturated and saturated domains [Grgic et al., 2005]. The failure surface is obtained from the maximal compressive strengths. The dilatancy surface is obtained from the dilatancy thresholds which are defined from the deviatoric stress-volumetric strain curve and indicate the onset of the dilatant volumetric deformation of the material. In the field of rock mechanics, this dilatancy threshold, which is obviously below the failure stress level, is often considered as the damage 


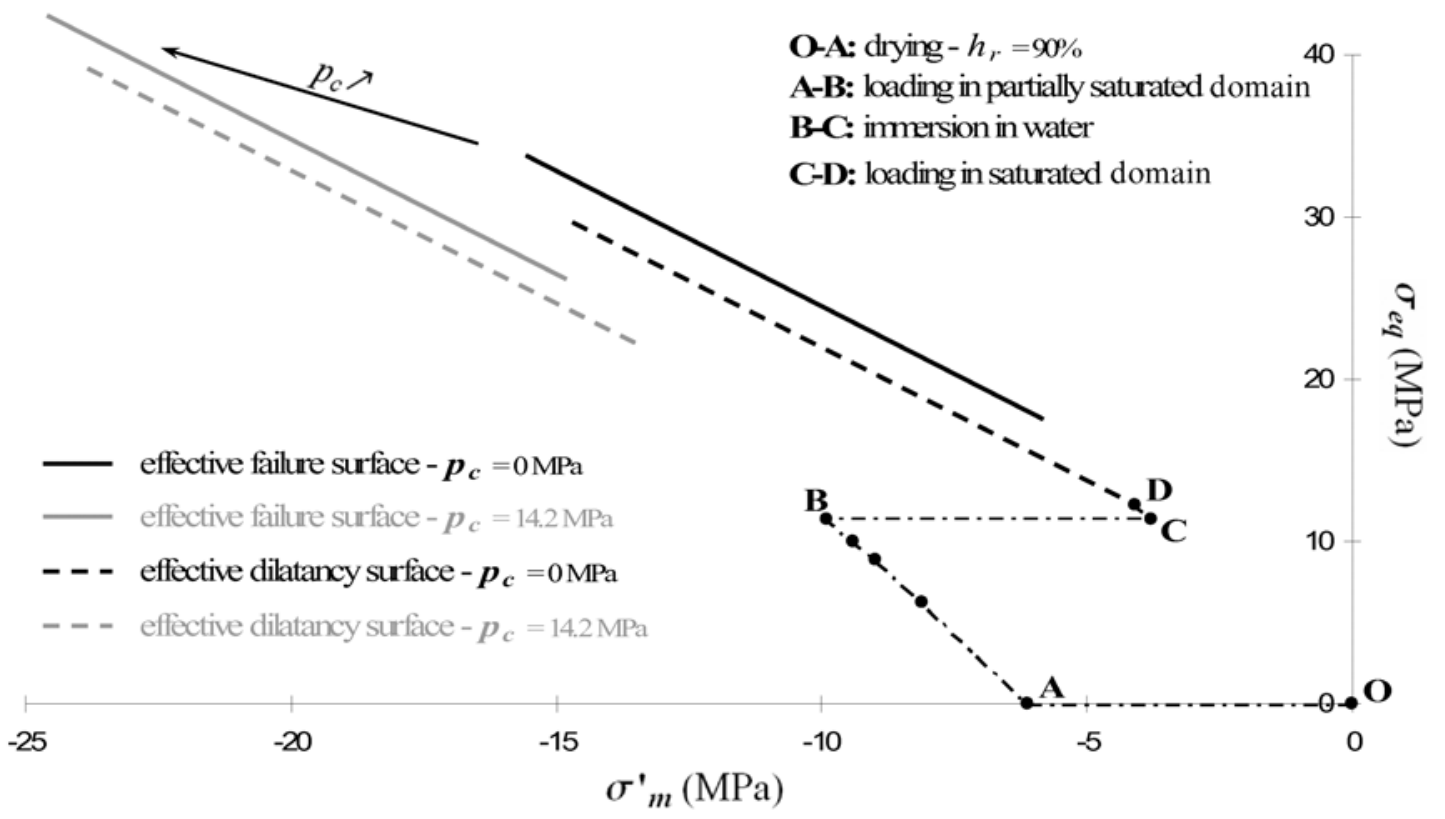

Figure 13. Loading path in the space of effective stress invariants (the convention of negative compressive stresses is used in this representation). Short-term (i.e., "instantaneous") failure and dilatancy surfaces of iron ore in partially saturated and saturated domains are taken from Grgic et al. [2005].

threshold, i.e., the onset of the unstable propagation of microcracks [e.g., Bieniawski, 1967; Martin and Chandler, 1994]. It corresponds therefore to the long-term strength since the unstable propagation of microcracks always leads to material failure after a certain period of time. Note that in a creep test, the stage of tertiary creep is often obtained for an axial stress corresponding to this short-term dilatancy threshold.

[45] In the partially saturated domain, dilatancy and failure thresholds are higher than in the saturated domain since the capillary attraction forces harden rocks. Indeed, these forces induce the increase in each component of the effective stress tensor exerted on the solid skeleton and in the effective mean stress $\sigma_{m}^{\prime}$ (see equations (9) and (10)). Therefore, the drying of a sample is equivalent to the application of a confining pressure since it results in a contraction of the material due to the reduction in size of the porous network and of microcrack porosity.

[46] The loading path is also shown in Figure 13. From O to A, the hydrous path corresponds to drying at $h_{r}=90 \%$. From $\mathrm{A}$ to $\mathrm{B}$, the loading path corresponds to uniaxial compression in the partially saturated domain. At point B, the stress state is still far from the dilatancy surface corresponding to $p_{c}=14.2 \mathrm{MPa}$, and therefore also far from the long-term strength. When water is introduced into the porous network (at B), $\pi=0$; the effective mean stress is therefore reduced significantly (equations (9) and (10)) and the stress state approaches the dilatancy surface of the saturated material $\left(p_{c}=0\right)$.

\subsection{Damage of the Rock in Relation to AE Activity: Samples $A$ and $B$}

[47] In the partially saturated domain (from points A to B in Figure 13), only transient (primary) creep is observed in the stress-strain curves (Figure 3); indeed, for each stress step, strain rate vanishes with time, as does the $\mathrm{AE}$ rate (Figure 8). In this domain, the elastic properties are almost constant (Figure 4), the inelastic volumetric strain remains small (Figure 3) and AE activity (Figure 8) is not very significant compared to that observed in the saturated domain. These three parameters, which are often used to quantify crack damage [e.g., Lin et al., 2004], indicate that crack damage mechanisms do not play a major role. In the partially saturated domain, the stress state is under the dilatancy surface (Figure 13) and AE activity and material deformation involve obviously inelastic processes for which many explanations could be given such as (1) the motion of interacting dislocations, as explained in section 5.1 and (2) the nucleation and propagation of microcracks which emit elastic energy partly as acoustic energy. Microcracks can develop continuously from very beginning of loading to failure, as remarked by many authors [e.g., Ohnaka and Mogi, 1982; Brace, 1978]. Indeed, as discussed in section 5.1., even at low levels of applied stress, there are many small regions of stress concentration in rocks: at grain and phase boundaries and at tips of microcracks and pores. Fracture would appear in each small region when the local stress exceeds the local strength, generating AE activity, even though such fractures will not cause failure of the entire body since they are confined to adjacent regions were the local stress is lower [Scholz, 1968a]. Under the dilatancy threshold, the contribution of the few induced microcracks to volumetric strain is small (Figure 3). It should also be noted that under triaxial loading, rock porosity may be reduced by an inelastic deformation of pores. This physical process, which is very efficient in generating AE [Zhang et al., 1990], induces the compaction of very porous materials like iron ore and acts against the increase in volumetric strain. However, hydrostatic compressive tests performed by 


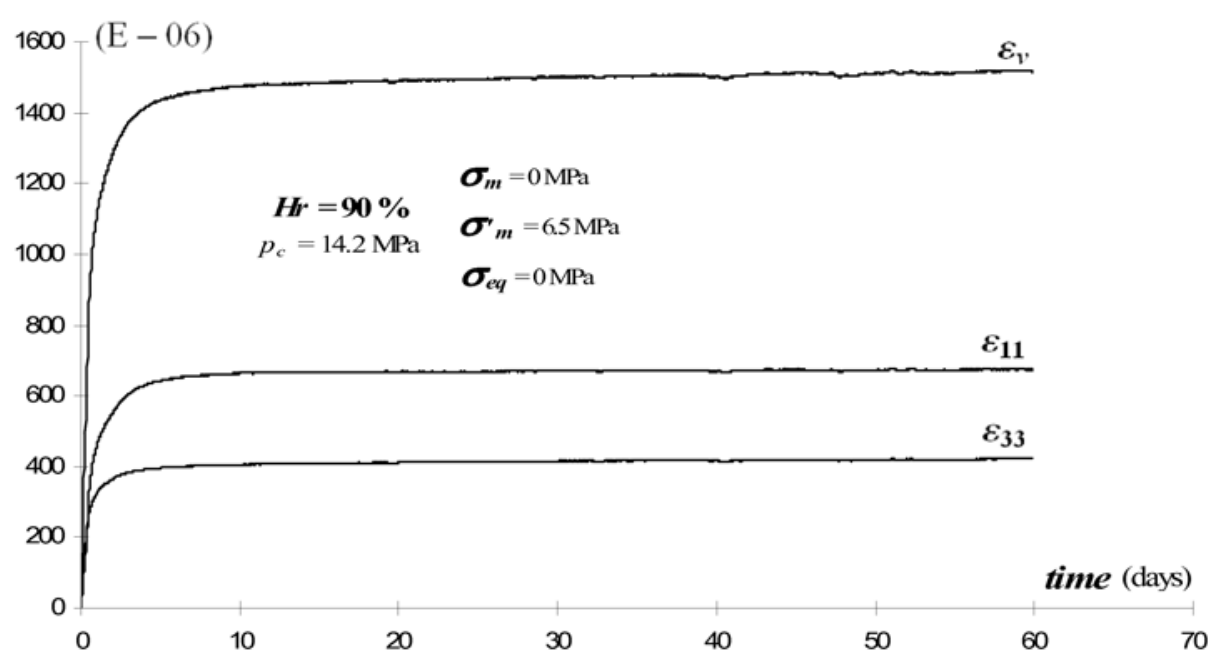

Figure 14. Evolutions of the deformations with time during the drying stage $\left(h_{r}=90 \%\right)$ in the hermetic cell (sample A).

Grgic et al. [2003] have shown that no pore collapse or grain crushing mechanisms are present in iron ore behavior.

[48] After immersion in water, since $\sigma_{m}^{\prime}$ decreases strongly, the stress state reaches the dilatancy surface of the saturated material (point $\mathrm{C}$ in Figure 13) and AE activity increases (Figures 8 and 9). Indeed, many authors [e.g., Ohnaka and Mogi, 1982; Lockner, 1993] have shown that the beginning of AE activity corresponds to the onset of dilatancy. In addition, the inelastic volumetric strain increases dramatically as observed in past studies [e.g., Ohnaka and Mogi, 1982] and Young's modulus decreases (Figure 4). All these parameters indicate that microfracturing activity accelerates and plays an important role in the creep process, as supported by experimental evidence [Lockner and Byerlee, 1977; Scholz, 1968a; Ohnaka, 1983], by in situ observations [Amitrano et al., 2005] and by numerical simulations [Amitrano and Helmstetter, 2006]. Poisson's ratio remains almost constant during the whole experiment (Figure 4) which may indicate isotropic damage.

[49] Generally speaking, the dilatancy threshold corresponds to the point at which existing cracks at small angles to the uniaxial compression axis begin to open. Beyond the dilatancy threshold, volumetric and radial inelastic strains increase due to the opening of induced microcracks. The tension axes, which are normal to the wing crack plane, are mainly oriented radially in the cylindrical sample and are parallel to the minimum radial principal stress $\sigma_{33}$, as shown by Manthei [2005] from the moment tensor analysis of AE events.

[50] In the partially saturated domain only primary creep is observed since the stress state is under the dilatancy surface. In addition, the volumetric strain evolves proportionally with the AE activity (Figure 8), as shown by many authors [e.g., Scholz, 1968a; Ohnaka, 1983; Baud and Meredith, 1997]. Immersion in water induces a significant increase in volumetric strain which is due to the dilation of the rock. Indeed, during the drying phase $\left(h_{r}=90 \%\right)$ in the hermetic cell (Figure 2), before the first stress level was applied, the contraction of the material due to the increase in the effective mean stress, induced significant elastic (i.e., reversible) volumetric strains, as illustrated in Figure 14. After immersion in water, the significant increase in the inelastic volumetric strain shown in Figure 3 takes also into account the elastic dilation due to the decrease in effective mean stress. This elastic dilation does not imply AE activity, thus explaining why volumetric strain increases proportionally much more than AE activity (Figure 8). This reversible elastic deformation also explains the decrease in axial strain in Figure 3.

[51] After this transitory stage of resaturation, volumetric deformation increases continuously, suggesting that timedependent microcracking plays the major role in the creep process. AE activity also increases continuously and the proportionality with volumetric strain remains constant up until at least 140 days. Beyond the dilatancy threshold, the applied stress is constant so the propagation of microcracks becomes unstable and the macroscopic failure of the entire body occurs (for $\sigma_{11}=12.3 \mathrm{MPa}$ ) after a tertiary phase visible in the AE activity.

[52] Figure 8 shows that the AE rate becomes much higher as stress increases and the sample becomes damaged. Indeed, damage evolves by increments of crack growth that produce acoustic emissions. Note that porous rocks like iron ore display in general a higher $\mathrm{AE}$ rate than less porous rocks [Dai and Labuz, 1997]. In addition, the statistical analysis of AE (Figures 9 and 10) shows that the relative number of high-energy events and the maximum event size are larger in the saturated domain, i.e., beyond the dilatancy threshold, than in the partially saturated domain, and continue to increase as the rock approaches failure. This means that the $b$ value decreases which is consistent with past observations [e.g., Ohnaka and Mogi, 1982; Scholz, 1968b; Mogi, 1981]. In particular, Mogi [1981] found a decrease in $b$ value before failure under a constant applied stress. This means that the number of emission events with higher energy increases dramatically in relative terms as the result of the crack interaction and crack coalescence which becomes more important as macroscopic failure approaches [Ohnaka and Mogi, 1982; Kranz, 1979]. These emission 
events with higher energy are certainly generated by larger size cracks.

[53] Our experimental observations are also in agreement with the recently proposed numerical model of Amitrano and Helmstetter [2006] for brittle creep in rocks. In this model, as the applied stress is increased, the AE size distribution shifts progressively from a law with exponential fall off for higher sizes to a power law without fall off, and the maximum event size is increased by several orders of magnitude. This concurs with the observations shown in Figures 9 and 10. It should be noted that this kind of change in the shape of seismic event size distribution has also been observed before the collapse of a chalk cliff which supposedly resulted from creep failure [Amitrano et al., 2005]. This suggests that our laboratory results may have interesting applications on a larger scale and for different types of rocks.

\subsection{Physicochemical Influence of Water on the Long- Term Strength of Iron Ore}

[54] Pore fluids also influence the time-dependent deformation and strength of porous rocks like iron ore in a physicochemical manner. Indeed, in chemically reactive environments, such as rocks exposed to atmospheric conditions, microcrack crack growth is assisted by the stress corrosion mechanism at crack tips [e.g., Anderson and Grew, 1977; Orowan, 1944; Charles, 1958a; Nara and Kaneko, 2005; Atkinson, 1984; Atkinson and Meredith, 1987], thus allowing the propagation of microcracks even at low stress levels. This subcritical stress corrosion cracking is the main cause of static fatigue and has been well demonstrated for silica glasses [e.g., Wiederhorn, 1967] and silicate minerals like quartz [Charles, 1959; Scholz, 1972]. It has also been demonstrated for many rock-forming minerals [Scholz, 1972] and silicate rocks like granite [Charles, 1959; Scholz, 1968a] in which static fatigue may develop within and between grains.

[55] Many authors [e.g., Zhu et al., 2005] have shown that the stress corrosion agent is water (liquid or vapor). In the case of silicate rocks, water chemically attacks the strained siloxane ( $\mathrm{Si}-\mathrm{O}-\mathrm{Si}$ ) bonds at the crack tip thus inducing bond rupture, aided by the tensile stress, and formation of terminal silanol $(\mathrm{Si}-\mathrm{OH})$ groups with weaker bonds:

$$
\equiv \mathrm{Si}-\mathrm{O}-\mathrm{Si} \equiv+\mathrm{H}_{2} \mathrm{O} \rightarrow 2[\equiv \mathrm{Si}-\mathrm{OH}]
$$

Indeed, chemical reaction rates in solids are known to depend on mechanical stress levels [e.g., Lawn, 1993] which modify activation energy barriers. It is well known that stress corrosion cracking is also facilitated at higher water vapor pressures [e.g., Meredith and Atkinson, 1985] and in water-saturated rocks [Waza et al., 1980; Meredith and Atkinson, 1983]. Indeed, water changes the activation energy of the chemical reaction (11) and increases the crack propagation velocity [Scholz, 1972; Atkinson, 1984, 1991]. Some authors [Wiederhorn et al., 1980; Charles, 1958b] have suggested that for rocks exposed to atmospheric conditions, crack velocity evolves with the stress intensity factor $K_{1}$ as

$$
\frac{d a}{d t}=\alpha p_{v}^{m} \exp \left[\left(-E a+\beta K_{1}\right) / R T\right]
$$

where $d a / d t$ is the crack velocity, $E a$ is the activation energy, and $\alpha, \beta$ and $m\left(m=1\right.$ if $\left.h_{r}>1 \%\right)$ are material constants.

[56] In this relation, crack velocity has an Arrhenius temperature dependence and is proportional both to the rate of the chemical reaction through its activation energy $E a$ (which represents a barrier to overcome) and to the water vapor pressure $p_{v}$. In addition, the crack velocity is aided by the stress whose intensity at the crack tip is given by $K_{1}$. Subcritical crack growth occurs when the stress intensity factor $K_{1}$ is less than the fracture toughness $K_{1 \mathrm{c}}$ and more than the stress corrosion limit $K_{0}$. The physical meaning of equation (12) is that if a constant stress is applied to a brittle rock in a corrosive environment, the high tensile stress at the crack tip accelerates the corrosion reaction there so that the cracks tend to lengthen until they reach the critical Griffith flaw length and propagate unstably [Scholz, 1968a; Martin, 1972]. In inhomogeneous materials like rocks, each small region, which can be considered homogeneous, will undergo static fatigue (i.e., weakening in time) but the resulting behavior of the whole body will be time-dependent microfracturing, resulting in creep. A similar equation, in which the applied stress is used instead of $K_{1}$, has been proposed by Scholz [1972] for the rate of microfracturing.

[57] Charles [1959] studied the static fatigue of a number of silicates and oxides and found them to be quite similar in behavior and he suggests that all silicate materials, for which the stress corrosion reaction (equation (11)) is applicable, should exhibit similar fatigue behavior. Many authors [e.g., Charles, 1959] have shown that the failure time depends on the level of applied stress and on humidity, and also has an Arrhenius temperature dependence. The following equations, similar to equation (12), have been found to represent the evolution of the failure time of quartz [Martin, 1972; Scholz, 1972] and of inhomogeneous silicate materials like rocks [Scholz, 1968a], respectively:

$$
\begin{aligned}
& t_{f}=t_{0} p_{v}^{-\alpha} \exp [(E a-x \sigma) / R T] \\
& t_{f}=\frac{1}{\beta} \exp \left[(E a / k T)+b\left(S-\sigma_{l}\right)\right]
\end{aligned}
$$

where $t_{0}, \alpha, x, \beta$, and $b$ are material constants, $k$ is Boltzmann's constant, $\sigma$ is the applied stress, $S$ is the strength without corrosion, and $\sigma_{l}$ is the local stress.

[58] We have identified many mineralogical reactions, leading to iron ore corrosion, in different samples of iron ore thanks to mineralogical analyses (SEM, electronic microprobe, Mössbauer spectroscopy) [Dagallier et al., 2002; Grgic et al., 2003]. Here after we propose the following phenomenological model for iron ore mineralogical evolution corresponding to the successive stages of mining exploitation.

[59] Before mining, rocks are saturated, interstitial water is chemically equilibrated with the rock and the $\mathrm{pH}$ is neutral due to the high carbonate content of iron ore and rocks comprising the overburden. Therefore, the rate of hydrolysis reactions, such as reaction (11), is negligible. In addition, these reactions are not assisted by stress since mine rooms have yet to be excavated and the deviatoric stress is not as large as in the mine pillars. Because of the anaerobic conditions, no oxidation reaction occurs either. 
Therefore, without anthropogenic disturbance, the mineralogical and mechanical state of iron ore will remain essentially constant.

[60] During mining, galleries are ventilated and rocks are partially saturated. Some samples have been taken in the areas of the mine where pillars are exposed to these aerobic environmental conditions over a long period (70 years), and analyzed. From a mechanical point of view, exposure to such conditions results in a significant decrease in strength and in characteristic surfaces of iron ore (represented in Figure 13) compared to healthy iron ore (i.e., before mining) [Grgic et al., 2003]. From a chemical point of view, the weathering of iron ore corresponds to a "mineralogical aging."

[61] First, the dissolution of interoolithic siderite $(\mathrm{FeCO})$, which cements ooliths and ensures the cohesion of the rock, releases ferrous iron $\mathrm{Fe}^{2+}$ through a hydrolysis reaction:

$$
\mathrm{FeCO}_{3}+\mathrm{CO}_{2}+\mathrm{H}_{2} \mathrm{O} \rightarrow \mathrm{Fe}^{2+}+2 \mathrm{HCO}_{3}^{-}
$$

Hydrolysis reactions (equations (11) and (14)) may occur with a higher rate if the $\mathrm{pH}$ of interstitial water is acid. The acidity depends on the quantity of dissolved $\mathrm{CO}_{2}$ and, thus, on the partial pressure of gaseous $\mathrm{CO}_{2}$, which is more significant in the air in pillars than in the atmospheric air, due to the respiration of microorganisms. Since rocks are partially saturated, acidity is not as well neutralized as in the saturated case, and the $\mathrm{pH}$ can locally be slightly acid. The oxidation of pyrite, contained in the rocks (argillites) in the roof of galleries, induces acid mine drainage (AMD) that percolates through pillars and also contributes to the acidity of the porous medium. Since the environmental conditions are aerobic, the liberated $\mathrm{Fe}^{2+}$ is oxidized immediately after release in solution. This oxidation may also occur inside the siderite; the mineral becomes unstable, which results in the release of $\mathrm{Fe}^{3+}$. Bacteriological analyses have shown that $\mathrm{Fe}^{2+}$ is also oxidized by certain bacteria (e.g., Thiobacillus ferrooxidans) if the conditions are aerobic $\left(\mathrm{O}_{2}\right.$ is the electron acceptor). This alteration of siderite, the proportion of which decreases with time, induces the breaking of diagenetic links that ensure the mechanical cohesion of iron ore.

[62] Once released, $\mathrm{Fe}^{2+}$ hydrolyzes when it comes in contact with $\mathrm{H}_{2} \mathrm{O}$ and forms ferric hydroxide (equation (15)) and hematite (equation (16)), the most dehydrated ferric oxide:

$$
\begin{gathered}
\mathrm{Fe}^{2+}+3 \mathrm{H}_{2} \mathrm{O} \rightarrow \mathrm{Fe}(\mathrm{OH})_{3}+3 \mathrm{H}^{+}+e^{-} \\
2 \mathrm{Fe}^{2+}+4 \mathrm{HCO}_{3}^{-}+\frac{1}{2} \mathrm{O}_{2}+4 \mathrm{H}_{2} \mathrm{O} \rightarrow \mathrm{Fe}_{2} \mathrm{O}_{3}+4 \mathrm{CO}_{2}+6 \mathrm{H}_{2} \mathrm{O}
\end{gathered}
$$

These neoformed iron oxides (i.e., "rust") correspond to the residue of the siderite alteration and they cover the ooliths (Figure 1c) and give weathered iron ore a red color. Moreover, these oxides contain aluminum, suggesting that they partly result from hydrolysis of berthierine $\left(\mathrm{Fe}^{2+}, \mathrm{Fe}^{3+}\right.$, $\mathrm{Al}, \mathrm{Mg})_{2-3}(\mathrm{Si}, \mathrm{Al})_{2} \mathrm{O}_{5}(\mathrm{OH})_{4}$ (ferriferous phyllosilicate) that releases ions such as $\mathrm{Al}^{3+}$ and $\mathrm{Fe}^{2+}$. This reaction break down the silicate in a way similar to that of equation (11):

$$
-\mathrm{SiO}-\mathrm{Fe}^{2+}+2 \mathrm{H}^{+} \rightarrow \mathrm{Fe}^{2+}+2 \mathrm{HO}-\mathrm{Si}
$$

In iron ore, berthierine, which is the mineral implied to undergo hydrolysis reactions like (11) and (17), constitutes a large fraction of the interoolithic cement and ensures the cohesion of the rock along with siderite [Dagallier et al., 2002]. Reactions (11) and ((14)-(17)) correspond to different forms of corrosion of iron ore, i.e., a deterioration of its mechanical properties with time due to reactions with its environment (moisture and oxygen).

[63] When mining operations end, mine flooding induces the resaturation of rocks. The rate of hydrolysis reactions ((11), (14), and (17)) decreases slightly since mine drainage is chemically equilibrated with the rocks $(\mathrm{pH} \sim 7)$. Conversely, the rate increases significantly because of the larger quantity of water, as illustrated by equation (12). Oxygen becomes limited (e.g., anaerobic environmental conditions) because it is rapidly used up by aerobic microorganisms, and this stops the occurrence of oxidation reactions $(15,16)$.

[64] Hydrolysis reactions ((11), (14), and (17)) are aided by the tensile stress at crack tips. Indeed, since galleries have been excavated, constant deviatoric stress is imposed on the pillars and high tensile stresses may induce the opening of microcracks, between grains, for example. The stress corrosion process will start at crack tips if the induced microcracks are connected to the porous network, allowing the transport of fluids and gases to crack tips. Indeed, studies have shown [e.g., Martin, 1972] that time-dependent crack growth is controlled by the rate at which corrosive agents (water) can reach the crack tip and this rate is higher in the saturated case.

[65] If aerobic environmental conditions are imposed in the galleries over a long period ( $\sim 70$ years $)$, this chemical aging process happens on a large scale; the whole interoolithic material is affected (Figure 1c), not just crack tips, and aging progresses right into the center of large rectangular pillars $(20 \mathrm{~m} \times 30 \mathrm{~m})$. The reactions described above play a major role in the long-term behavior of iron ore, even though they evolve over a longer time scale than creep tests on samples A and B that reproduce the hydration history imposed on iron ore rocks in the mine. Since the duration of creep experiments is very short compared to the time scales of mining, hydrolysis reactions (equations (11), (14), and (17)) may only occur at crack tips where they are accelerated by stress. This stress corrosion at crack tips diminishes the energy barrier for crack growth and explains the significant increase in $\mathrm{AE}$ rate and $\mathrm{AE}$ energy after water saturation, according to equation (12).

\section{Summary and Conclusions}

[66] We studied the long-term behavior of a porous rock (iron ore) through multistep uniaxial creep tests under both partially saturated conditions, for which the water vapor pressure is controlled, and saturated conditions. The inelastic deformation of iron ore is of semibrittle type, i.e., it is related to plastic (i.e., dislocation motion) and microcracking processes. The plastic process was identified from multistep creep tests with inverse loadings and acoustic 
emissions (AE) measurements, providing evidence of the reversible motion of dislocations. The microcracking process was analyzed by AE measurements. In the partially saturated regime, for which only transient creep is observed, AE activity is not significant and the induced microcracks generate insignificant dilatant volumetric strains. In the water-saturated regime, the addition of water induces a marked increase in AE activity and dilatant inelastic volumetric strains, whereas the Young modulus and the $b$ value decrease as the rock approaches failure, indicating that microfracturing plays an important role in the creep process.

[67] First, water influences the static fatigue of iron ore through hydromechanical coupling. Indeed, when water is introduced into the porous network, the annihilation of the capillary attraction forces, which act as a confining pressure, lessens the effective mean stress, thereby weakening the rocks. Second, since iron ore in the presence of water is a chemically reactive system, water strongly influences the static fatigue through physicochemical mechanisms. Indeed, ferriferous phyllosilicates and siderite, which constitute the interoolithic cement, are hydrolyzed, and this reaction, if assisted by high tensile stresses at the cracks tips, yields subcritical stress corrosion cracking.

[68] Within the framework of underground iron mines, corrosion reactions of course evolve over a larger time scale than in creep tests. After many years this may lead to a significant decrease in the intrinsic strength of iron ore, since corrosion reactions develop in the whole interoolithic material, not only at crack tips where they are assisted by stress and where they accelerate the microcracking process. On a large scale, static fatigue and aging, caused by these mineralogical transformations, play a major role in the longterm behavior of iron ore. They are probably the main mechanisms responsible for certain underground mine collapses in Lorraine (France). Therefore, knowledge of these processes is important for estimating the long-term stability of such rock structures. Furthermore, the triggering of some collapses by water injection is likely to involve intrinsic weakening by stress corrosion and aging as described above along with mechanical pore pressure effects.

[69] Acknowledgments. This research was carried out thanks to subsidies from the Ministries for Industry and Research and the Lorraine Region within the GISOS (http://www.gisos.org) framework. The authors express their gratitude to these organizations. Furthermore, D. Amitrano thanks French program INSU-Catell and EU program Trigs for support.

\section{References}

Amitrano, D., and A. Helmstetter (2006), Brittle creep, damage and time to failure in rocks, J. Geophys. Res., 111, B11201, doi:10.1029/ 2005JB004252.

Amitrano, D., J. R. Grasso, and G. Senfaute (2005), Seismic precursory patterns before a cliff collapse and critical-point phenomena, Geophys. Res. Lett., 32, L08314, doi:10.1029/2004GL022270.

Anderson, O. L., and P. C. Grew (1977), Stress corrosion theory of crack propagation with application to geophysics, Rev. Geophys. Space Phys. 15, 77-104, doi:10.1029/RG015i001p00077.

Ashby, M. F. (1971), The deformation of plastically non-homogeneous alloys, in Strengthening Methods in Crystals, edited by A. Kelly and R. B. Nicholson, pp. 137-192, Appl. Sci., London.

Atkinson, B. K. (1984), Subcritical crack growth in geological materials, J. Geophys. Res., 89(B6), 4077-4114, doi:10.1029/JB089iB06p04077.

Atkinson, B. K. (1991), Fracture Mechanics of Rock, 534, pp. Academic, London.

Atkinson, B. K., and P. G. Meredith (1987), The theory of subcritical crack growth with applications to minerals and rocks, in Fracture Mechanics of Rock, edited by B. K. Atkinson, pp. 111-166, Academic, London.
Bailey, R. W. (1926), Note on the softening of strain hardening metals and its relation to creep, J. Inst. Met., 35, 27-40.

Barber, D. J., and H.-R. Wenk (1979), On geological aspects of calcite microstructure, Tectonophysics, 54, 45-60, doi:10.1016/00401951(79)90111-2.

Baud, P., and P. G. Meredith (1997), Damage accumulation during triaxial creep of Darley Dale sandstone from pore volumometry and acoustic emission, Int. J. Rock Mech. Min. Sci. Geomech. Abstr., 34, 371, doi:10.1016/S0148-9062(97)00019-3.

Beeman, M. L., and D. L. Kohlstedt (1988), Dislocation density: Stress relationships in natural and synthetic sodium chloride, Tectonophysics, 148, 147-161, doi:10.1016/0040-1951(88)90167-9.

Bieniawski, Z. T. (1967), Mechanism of brittle fracture of rock, parts I, II and III, Int. J. Rock Mech. Min. Sci. Geomech. Abstr., 4, 395-430, doi:10.1016/0148-9062(67)90030-7.

Blum, W. (2001), Creep of crystalline materials: Experimental basis, mechanisms and models, Mater. Sci. Eng., 319-321, 8-15, doi:10.1016/ S0921-5093(00)02010-4

Boyko, V. S., R. I. Garber, and A. M. Kossevich (1994), Reversible Crystal Plasticity, 295 pp., Am. Inst. of Phys. Press, New York.

Brace, W. F. (1978), Volume changes during fracture and frictional sliding: A review, Pure Appl. Geophys., 116, 603-614, doi:10.1007/ BF00876527.

Charles, R. J. (1958a), Static fatigue of glass, J. Appl. Geophys., 27, 1549.

Charles, R. J. (1958b), Static fatigue of glass II, J. Appl. Geophys., 29, $1554-1560$.

Charles, R. J. (1959), The strength of silicate glasses and some crystalline oxides, in Proceedings of the International Conference on Fracture, pp. 225-250, MIT Press, Cambridge, Mass.

Coussy, O. (1995), Mechanics of Porous Continua, 2nd ed., John Wiley, Chichester, U. K

Dagallier, G., D. Grgic, and F. Homand (2002), Mineralogical and microtextural characterization of the anthropic-origin ageing of iron ore in Lorraine (France), C. R. Geosci., 334, 455-462, doi:10.1016/S16310713(02)01783-2.

Dai, S. T., and J. F. Labuz (1997), Damage and failure analysis of brittle materials by acoustic emission, J. Mater. Civ. Eng., 9(4), 200-205, doi:10.1061/(ASCE)0899-1561(1997)9:4(200).

De Bresser, J. H. P. (1996), Steady state dislocation densities in experimentally deformed calcite materials: Single crystals versus polycrystals, J. Geophys. Res., 101(B10), 22,189-22,201, doi:10.1029/96JB01759.

Dell'Angelo, L. N., and D. L. Olgaard (1995), Experimental deformation of fine-grained anhydrite: Evidence for dislocation and diffusion creep, J. Geophys. Res., 100(B8), 15,425-15,440, doi:10.1029/95JB00956.

Dul'kin, E. A., V. G. Gavrilyachenko, and O. E. Fesenko (1997), Acoustic emission investigation of phase transitions in antiferromagnetic $\mathrm{PbZrO}_{3}$ and $\mathrm{PbHfO}_{3}$ crystals, Phys. Solid State, 39(4), 654-665, doi:10.1134/ 1.1129947.

Grgic, D., F. Homand, and D. Hoxha (2003), A short- and long- term rheological model to understand the collapses of iron mines in Lorraine, France, Comput. Geotech., 30, 557-570, doi:10.1016/S0266352X(03)00074-0.

Grgic, D., R. Giot, F. Homand, and A. Giraud (2005), Effect of suction on the mechanical behavior of iron ore rock, Int. J. Numer. Anal. Methods Geomech., 29, 789-827, doi:10.1002/nag.438.

Gutenberg, B., and C. F. Richter (1954), Seismicity of the Earth and Associated Phenomena, Princeton Univ. Press, Princeton

Hoxha, D., A. Giraud, and F. Homand (2005), Modelling long-term behaviour of a natural gypsum rock, Mech. Mater., 37(12), 1223-1241, doi:10.1016/j.mechmat.2005.06.002.

Hunsche, U., and A. Hampel (1999), Rock Salt-The mechanical properties of the host rock material for a radioactive waste repository, Eng. Geol. Amsterdam, 52, 271-291, doi:10.1016/S0013-7952(99)00011-3.

International Organization for Standardization (2005), ISO 483:2005, Plastics-Small enclosures for conditioning and testing using aqueous solutions to maintain the humidity at a constant value, Geneva, Switzerland.

Kennedy, L. A., and J. M. Logan (1998), Microstructures of cataclasites in a limestone-on-shale thrust fault: Implications for low-temperature recrystallization of calcite, Tectonophysics, 295, 167-186, doi:10.1016/S0040 1951(98)00119-X

Kennedy, L. A., and J. C. White (2001), Low-temperature recrystallization in calcite: Mechanisms and consequences, Geology, 29(11), 1027-1030, doi:10.1130/0091-7613(2001)029<1027:LTRICM $>2.0$. CO;2.

Kranz, R. L. (1979), Crack growth and development during creep of Barre granite, Int. J. Rock Mech. Min. Sci. Geomech. Abstr., 16, 23-35, doi:10.1016/0148-9062(79)90772-1.

Kranz, R. (1980), The effect of confining pressure and difference stress on static fatigue of granite, J. Geophys. Res., 85(B4), 1854-1866, doi:10.1029/JB085iB04p01854 
Kranz, R., W. Harris, and N. Carter (1982), Static fatigue of Granite at $20{ }^{\circ} \mathrm{C}$, Geophys. Res. Lett., 9(1), 1-4, doi:10.1029/GL009i001p00001.

Lajtai, E. Z., R. H. Schmidtke, and L. P. Bielus (1987), The effect of water on the time-dependent deformation and fracture of a granite, Int. J. Rock Mech. Min. Sci. Geomech. Abstr., 24, 247-255, doi:10.1016/0148 9062(87)90179-3.

Lawn, B. R. (1993), Fracture of Brittle Solids, 2nd ed., Cambridge Univ. Press, Cambridge, U. K.

Lin, Q. X., L. G. Tham, M. R. Yeung, and P. K. K. Lee (2004), Failure of granite under constant loading, Int. J. Rock. Mech. Mining Sci., 41, suppl. $1,1 \mathrm{~A} 09,1-6$

Liu, J., J. M. Walter, and K. Weber (2002), Fluid-enhanced low-temperature plasticity of calcite marble: Microstructures and mechanisms, Geology, 30(9), 787-790, doi:10.1130/0091-7613(2002)030<0787:FELTPO $>$ 2.0.CO;2.

Lockner, D. A. (1993), The role of acoustic emission in the study of rock fracture, Int. J. Rock Mech. Min. Sci. Geomech. Abstr., 30, 883-899, doi:10.1016/0148-9062(93)90041-B.

Lockner, D., and J. Byerlee (1977), Acoustic emission and creep in rock at high confining pressure and differential stress, Bull. Seismol. Soc. Am. $67,247-258$

Manthei, G. (2005), Characterization of acoustic emission sources in a rock salt specimen under triaxial compression, Bull. Seismol. Soc. Am., 95 , 1674-1700, doi:10.1785/0120040076.

Martin, C. D., and N. A. Chandler (1994), The progressive fracture of Lac du Bonnet granite, Int. J. Rock Mech. Min. Sci. Geomech. Abstr., 31 , 643-659, doi:10.1016/0148-9062(94)90005-1.

Martin, R. J. (1972), Time-dependent crack growth in quartz and its application to the creep of rocks, J. Geophys. Res., 77(8), 1406-1419, doi:10.1029/JB077i008p01406.

Masuda, K. (2001), Effects of water on rock strength in a brittle regime, J. Struct. Geol., 23, 1653-1657, doi:10.1016/S0191-8141(01)00022-0.

Masuda, K., H. Mizutani, I. Yamada, and Y. Imanishi (1988), Effects of water on time-dependent behavior of granite, J. Phys. Earth, 36(6), 291-313.

Meredith, P. G., and B. K. Atkinson (1983), Stress corrosion and acoustic emission during tensile crack propagation in Whin Sill dolerite and other basic rocks, Geophys. J. R. Astron. Soc., 75, 1-21.

Meredith, P. G., and B. K. Atkinson (1985), Fracture toughness and subcritical crack growth during high-temperature tensile deformation of Westerly granite and Black gabbro, Phys. Earth Planet. Inter., 39, 33-51, doi:10.1016/0031-9201(85)90113-X.

Miguel, M.-C., A. Vesignani, S. Zapperi, J. Weiss, and J. R. Grasso (2001) Intermittent dislocation flow in viscoplastic deformation, Nature, 410 667-671, doi:10.1038/35070524.

Mlakar, V., F. P. Hassani, and M. Momayez (1993), Crack development and acoustic emission in Potash Rock, Int. J. Rock Mech. Min. Sci. Geomech. Abstr., 30, 305-319, doi:10.1016/0148-9062(93)92732-6.

Mogi, K. (1981), Earthquake prediction program in Japan, in Earthquake Prediction: An International Review, Maurice Ewing Ser, vol. 4, edited by D. W. Simpson and P. G. Richards, pp. 635-666, AGU, Washington, D. C.

Nara, Y., and K. Kaneko (2005), Study of subcritical crack growth in andesite using the double torsion test, Int. J. Rock Mech. Min. Sci., 42, 521-530, doi:10.1016/j.ijrmms.2005.02.001.

Natsik, V. D., L. S. Fomenko, and S. V. Lubenets (2003), Elastic shape memory effect in $\mathrm{In}-\mathrm{Pb}$ alloys in the temperature range $0.48-180 \mathrm{~K}$, Cent. Eur. J. Phys., 1, 235-245, doi:10.2478/BF02476294.

Nemat-Nasser, S., and M. Obata (1988), Microcrack model of dilatancy in brittle materials, J. Appl. Mech., 55, 24-35.

Newman, J., and G. Mitra (1994), Fluid-influenced deformation and recrystallization of dolomite at low temperatures along a natural fault zone, Mountain City window, Tennessee, Geol. Soc. Am. Bull., 106, 12671280, doi:10.1130/0016-7606(1994)106<1267:FIDARO>2.3.CO;2.

Ohnaka, M. (1983), Acoustic emission during creep of brittle rock, Int J. Rock Mech. Min. Sci. Geomech. Abstr., 20, 121-134, doi:10.1016/ 0148-9062(83)91302-5

Ohnaka, M., and K. Mogi (1982), Frequency characteristics of acoustic emission in rocks under uniaxial compression and its relation to the fracturing process to failure, J. Geophys. Res., 87(B5), 3873-3884, doi:10.1029/JB087iB05p03873.

Orowan, E. (1944), The fatigue of glass under stress, Nature, 154, $341-$ 343, doi:10.1038/154341a0.
Orowan, E. (1946), The creep of metals, J. West Scotland Iron Steel Inst., $54,45-68$.

Rehbinder, P. A., and V. Lichtman (1957), Effect of surface active media on strain and rupture in solids, in Proceedings of the Second International Congress of Surface Activity, vol. III, Electrical Phenomena. Solid/Liquid Interface, edited by J. H. Schulman, pp. 563-580, Academic, New York.

Renner, J., B. Evans, and G. Siddiqi (2002), Dislocation creep of calcite J. Geophys. Res., 107(B12), 2364, doi:10.1029/2001JB001680.

Rutter, E. H. (1972), The influence of interstitial water on the rheological behaviour of calcite rocks, Tectonophysics, 14, 13-33, doi:10.1016/ 0040-1951(72)90003-0.

Rutter, E. H. (1974), The influence of temperature, strain rate and interstitial water in the experimental deformation of calcite rocks, Tectonophysics, 22, 311-334, doi:10.1016/0040-1951(74)90089-4.

Sammonds, P. R., P. G. Meredith, J. B. Gomez, and I. G. Main (1995), The interaction between pore fluid pressure and crack damage evolution in rocks and rock structures from acoustic emission data, J. Acoust. Emission, $13, \mathrm{~S} 21-\mathrm{S} 28$

Scholz, C. H. (1968a), Mechanism of Creep in Brittle Rock, J. Geophys. Res., 73(10), 3295-3302, doi:10.1029/JB073i010p03295.

Scholz, C. H. (1968b), The frequency magnitude relation of microfracturing in rock and its relation to earthquakes, Bull. Seismol. Soc. Am., 58, $399-415$.

Scholz, C. H. (1972), Static fatigue of quartz, J. Geophys. Res., 77(11), 2104-2114, doi:10.1029/JB077i011p02104.

Ter Heege, J. H., J. H. P. De Bresser, and C. J. Spiers (2005), Rheological behaviour of synthetic rocksalt: The interplay between water, dynamic recrystallization and deformation mechanisms, J. Struct. Geol., 27, $948-$ 963, doi:10.1016/j.jsg.2005.04.008.

Urai, J. L., and C. J. Spiers (2007), The effect of grain boundary water on deformation mechanisms and rheology of rocksalt during long-term deformation, in The Mechanical Behavior of Salt-Understanding of THMC Processes in Salt: Proceedings of the 6th Conference (SaltMech6), Hannover, Germany, 22-25 May 2007, edited by M. Wallner, K. Lux, W. Minkley, and H. Hardy Jr., CRC Press, Boca Raton, Fla.

Urai, J. L., C. J. Spiers, H. J. Zwart, and G. S. Lister (1986), Weakening of rock salt by water during long-term creep, Nature, 324, 554-557, doi:10.1038/324554a0.

Waza, T., K. Kurita, and H. Mizutani (1980), The effect of water on the subcritical crack growth in silicate rocks, Tectonophysics, 67, 25-34, doi:10.1016/0040-1951(80)90162-6.

Weiss, J., J.-R. Grasso, M.-C. Miguel, A. Vespignani, and S. Zapperi (2001), Complexity in dislocation dynamics: Experiments, Mater. Sci. Eng. A, 309-310, 360-364, doi:10.1016/S0921-5093(00)01633-6.

Wiederhorn, S. M. (1967), Influence of water vapor on crack propagation in soda-lime glass, J. Am. Ceram. Soc., 50, 407-414, doi:10.1111/j.11512916.1967.tb15145.x.

Wiederhorn, S. M., E. R. Fuller Jr., and R. Thomson (1980), Micromechanisms of crack growth in ceramics and glasses in corrosive environments, Metal Sci., 14, 450-458.

Zeuch, D. H. (1982), Ductile faulting, dynamic recristallization, and grain size sensitive flow of olivine, Tectonophysics, 83, 293-308, doi:10.1016/ 0040-1951(82)90024-5.

Zhang, J., T.-F. Wong, T. Yanagidani, and D. M. Davis (1990), Pressureinduced microcracking and grain crushing in Berea and Boise sandstones. Acoustic emission and quantitative microscopy measurements, Mech. Mater., 9(1), 1-15, doi:10.1016/0167-6636(90)90026-C.

Zhu, T., J. Li, X. Lin, and S. Yip (2005), Stress-dependent molecular pathways of silica-water reaction. Acoustic emission and quantitative microscopy measurements, J. Mech. Phys. Solids, 53, 1597-1623, doi:10.1016 j.jmps.2005.02.002.

D. Amitrano, LIRIGM, Université Joseph Fourier, Maison des Géosciences, 1381 rue de la Piscine, B.P. 53, F-38041, Grenoble CEDEX 9, France. (david.amitrano@ujf-grenoble.fr)

D. Grgic, Laboratoire Environnement, Géomécanique et Ouvrages, Nancy Université, rue du Doyen Marcel Roubault, B.P. 40, F-54501 Vandoeuvre-lès-Nancy, France. (dragan.grgic@ensg.inpl-nancy.fr) 